\title{
Numerical simulation of bar and island morphodynamics in anabranching megarivers
}

\author{
A. P. Nicholas, ${ }^{1}$ P. J. Ashworth, ${ }^{2}$ G. H. Sambrook Smith, ${ }^{3}$ and S. D. Sandbach ${ }^{1,2}$ \\ Received 7 December 2012; revised 31 July 2013; accepted 10 August 2013.
}

[1] Bar and island morphodynamics in the world's largest anabranching rivers are investigated using a new numerical model of hydrodynamics, sediment transport, bank erosion, and floodplain development, operating over periods of several hundred years. Simulated channel morphology is compared to that of natural rivers and shown to be realistic, both in terms of the statistical characteristics of channel width, depth, and bar shape distributions, and mechanisms of unit bar, compound bar, and island evolution. Results demonstrate that bar and island stability may be sensitive to hydrologic regime, because greater variability in flood magnitude encourages the formation of emergent bars that can be stabilized by vegetation colonization. Simulations illustrate a range of mechanisms of unit bar generation that are linked to local bed or bank instabilities. This link may explain the reduced frequency of unit bars observed in some large anabranching rivers that are characterized by stable vegetated islands and slow rates of channel change. Model results suggest that the degree to which sand-sized bed material is carried in suspension likely represents an important control on bar morphodynamics and channel network evolution, because of its influence on sand transport direction. Consequently, differences in the partitioning of the total sand load between bed load and suspension may provide a partial explanation for contrasting styles of anabranching in the world's largest sand-bed rivers. These results highlight a need for spatially-distributed flow and sediment transport data sets from large rivers, in order to support improved parameterizations of sand transport mechanics in morphodynamic models.

Citation: Nicholas, A. P., P. J. Ashworth, G. H. Sambrook Smith, and S. D. Sandbach (2013), Numerical simulation of bar and island morphodynamics in anabranching megarivers, J. Geophys. Res. Earth Surf., 118, doi:10.1002/jgrf.20132.

\section{Introduction}

[2] Big rivers play a central role in the drainage and basin sedimentation of the Earth [Potter, 1978; Milliman and Meade, 1983; Hovius and Leeder, 1998; Fielding et al., 2012] and are important drivers of global-scale sediment flux, carbon sequestration, water resources, and ecological diversity [Gupta, 2007; Latrubesse, 2008; Syvitski and Kettner, 2011]. The world's largest rivers share several common characteristics. For example, they are predominantly sand-bed channels, with high mean annual discharges $\left(>10,000 \mathrm{~m}^{3} \mathrm{~s}^{-1}\right)$, low gradients $\left(<10 \mathrm{~cm} \mathrm{~km}^{-1}\right)$, high widths $(1-10 \mathrm{~km})$ and width: depth ratios (30-200), and multiple channels, also known as an "anabranching" channel pattern [cf. Latrubesse, 2008;

\footnotetext{
${ }^{1}$ College of Life and Environmental Science, University of Exeter,

${ }^{2}$ Division of Geography and Geology, School of Environment and Technology, University of Brighton, Brighton, UK.

${ }^{3}$ School of Geography, Earth and Environmental Sciences, University of Birmingham, Birmingham, UK.

Corresponding author: A. P. Nicholas, College of Life and Environmental Science, University of Exeter, Rennes Dr., Exeter EX4 4RJ, UK. (A.P.Nicholas@exeter.ac.uk)

(C)2013. American Geophysical Union. All Rights Reserved. 2169-9003/13/10.1002/jgrf.20132
} Exeter, UK.
Carling et al., 2013] (Figure 1). Despite these similarities, large rivers are characterized by remarkable diversity in terms of channel, bar and island morphology, rates of evolution, and hydrological connectivity to their floodplains [Orfeo and Stevaux, 2002; Ramonell et al., 2002; Latrubesse and Franzinelli, 2005; Best et al., 2007; Day et al., 2008; Assine and Silva, 2009; Rozo et al., 2012; Trigg et al., 2012; Lewin and Ashworth, 2013]. Moreover, the geomorphic functioning of large rivers remains poorly understood, due to the logistical constraints on data collection in channels that are often kilometers wide and $>10 \mathrm{~m}$ deep [Ashworth and Lewin, 2012], and the problems that are inherent in applying and evaluating numerical models of large river morphodynamics [Kleinhans, 2010]. Consequently, many important questions concerning the functioning and evolution of large rivers remain to be answered.

[3] Large anabranching rivers are characterized by substantial differences in rates of bank erosion, which vary from up to a kilometer during individual flood seasons (e.g., on the Jamuna, Bangladesh) [Ashworth et al., 2000; Khan and Islam, 2003; Best et al., 2007] to almost no channel movement for several decades (e.g., along sections of the Amazon left bank) [Rozo et al., 2012]. While high bank erodibility clearly influences channel dynamics [Bristow, 1987; Murray and Paola, 1994], it does not appear to be essential to drive anabranching [Nanson and Knighton, 1996; Kleinhans et al., 

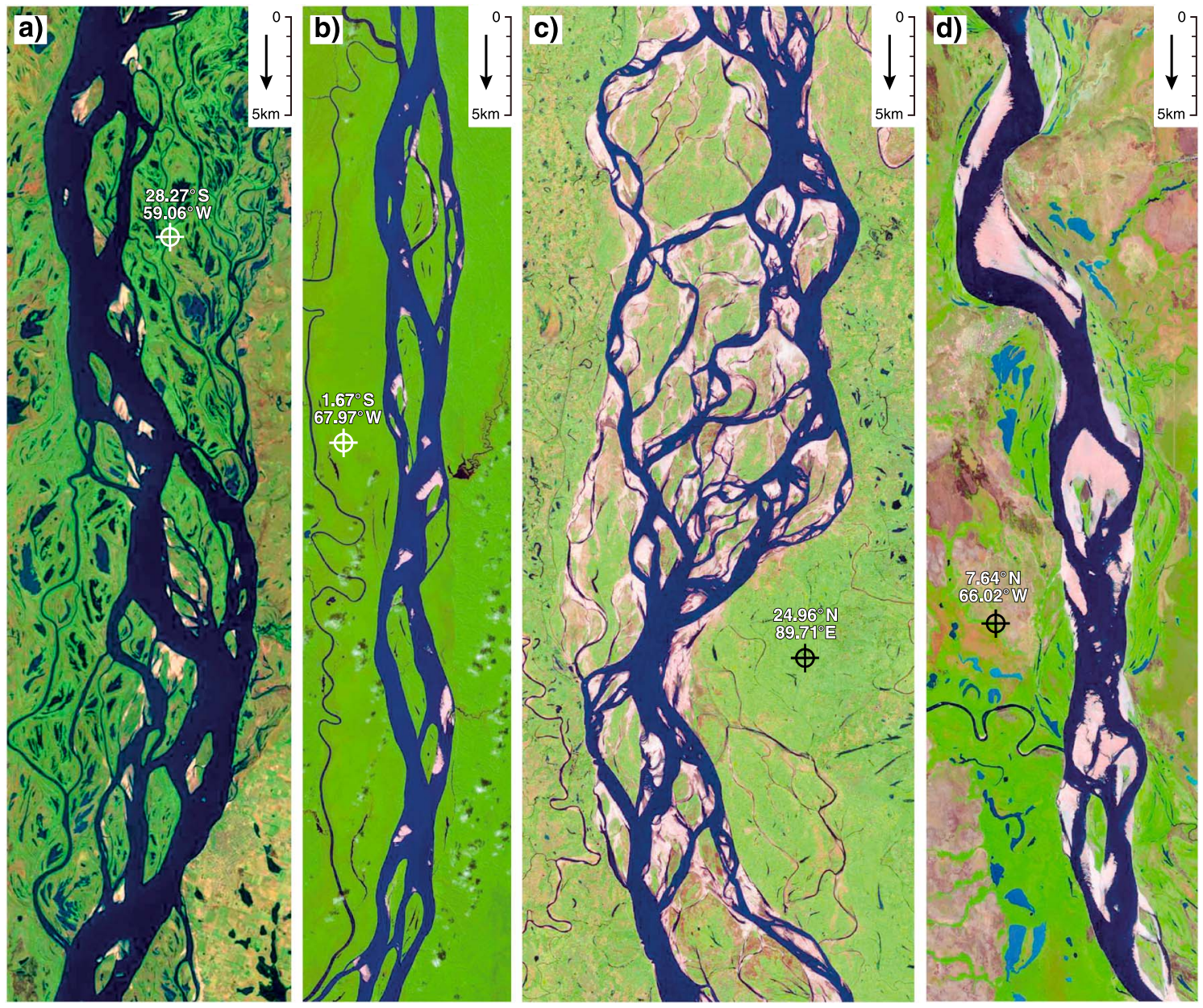

Figure 1. Examples of large anabranching sand-bed rivers: (a) Paraná, Argentina; (b) Japurá, Brazil; (c) Jamuna, Bangladesh; and (d) Orinoco, Venezuela. Flow is from top to bottom (indicated by the arrow). Landsat imagery courtesy of the U.S. Geological Survey.

2012]. Moreover, the interactions between bar construction and bank erosion (e.g., "bar push" versus "bank pull") remain poorly understood in large anabranching rivers, although recent research in smaller gravel-bed channels demonstrate that they are likely important [e.g., Allmendinger et al., 2005; Dunne et al., 2010; Parker et al., 2011]. The roles of vegetation and hydrologic regime as controls on large river morphology are equally unclear. For example, vegetation has been shown both to suppress and promote multithread channels [Nanson and Knighton, 1996; Gurnell et al., 2001; Eaton et al., 2010; Tal and Paola, 2010], while recent studies have argued that it has virtually no effect on the geometry of large rivers [Eaton and Giles, 2009]. Moreover, while field studies have identified the role of variable discharge in driving braiding [Fahnestock and Bradley, 1973; Gurnell et al., 2001], laboratory experiments have demonstrated that it is not a prerequisite [Ashmore, 1982, 1991; Bertoldi et al., 2009] and that such variability may be critical in encouraging the formation of single-thread channels, by giving vegetation the opportunity to colonize freshly deposited sediment [ Tal and Paola, 2010]. These complexities are more difficult to resolve in the case of large rivers, due to the logistical problems involved in undertaking process-based studies of longterm channel evolution, and because of scaling issues inherent in laboratory modeling [Peakall et al., 1996; Paola et al., 2009; van Dijk et al., 2012] that mean classical dynamic scaling of large sand-bed rivers in laboratory channels is virtually impossible.

[4] Mechanisms of bar and island formation have been described for several large anabranching rivers, including the Amazon [Mertes et al., 1996; Latrubesse and Franzinelli, 2002; Rozo et al., 2012], Jamuna [Ashworth et al., 2000; Best et al., 2007], Negro [Latrubesse and Franzinelli, 2005], and Paraná [Orfeo and Stevaux, 2002; Ramonell et al., 2002; Sambrook Smith et al., 2009]. In the current paper, we adopt a simple distinction between bars and islands based on the absence (bars) and presence (islands) of vegetation, although we note that this also results in differences in geometry and stability (discussed below). When referring to bars, we differentiate between unit bars (migrating lobate bed forms with heights and lengths that scale with channel depth and width, respectively) [Smith, 1974; Bridge, 2003], and compound bars that are larger, more complex features. The latter are constructed by multiple phases of accretion and reworking involving stacking of unit bars, dunes, and smaller bed forms [Best et al., 2003; Bridge, 2003; Sambrook Smith et al., 2009; Ashworth et al., 2011]. Examples of each of these features are shown in Figure 2. Previous studies [e.g., Mertes 

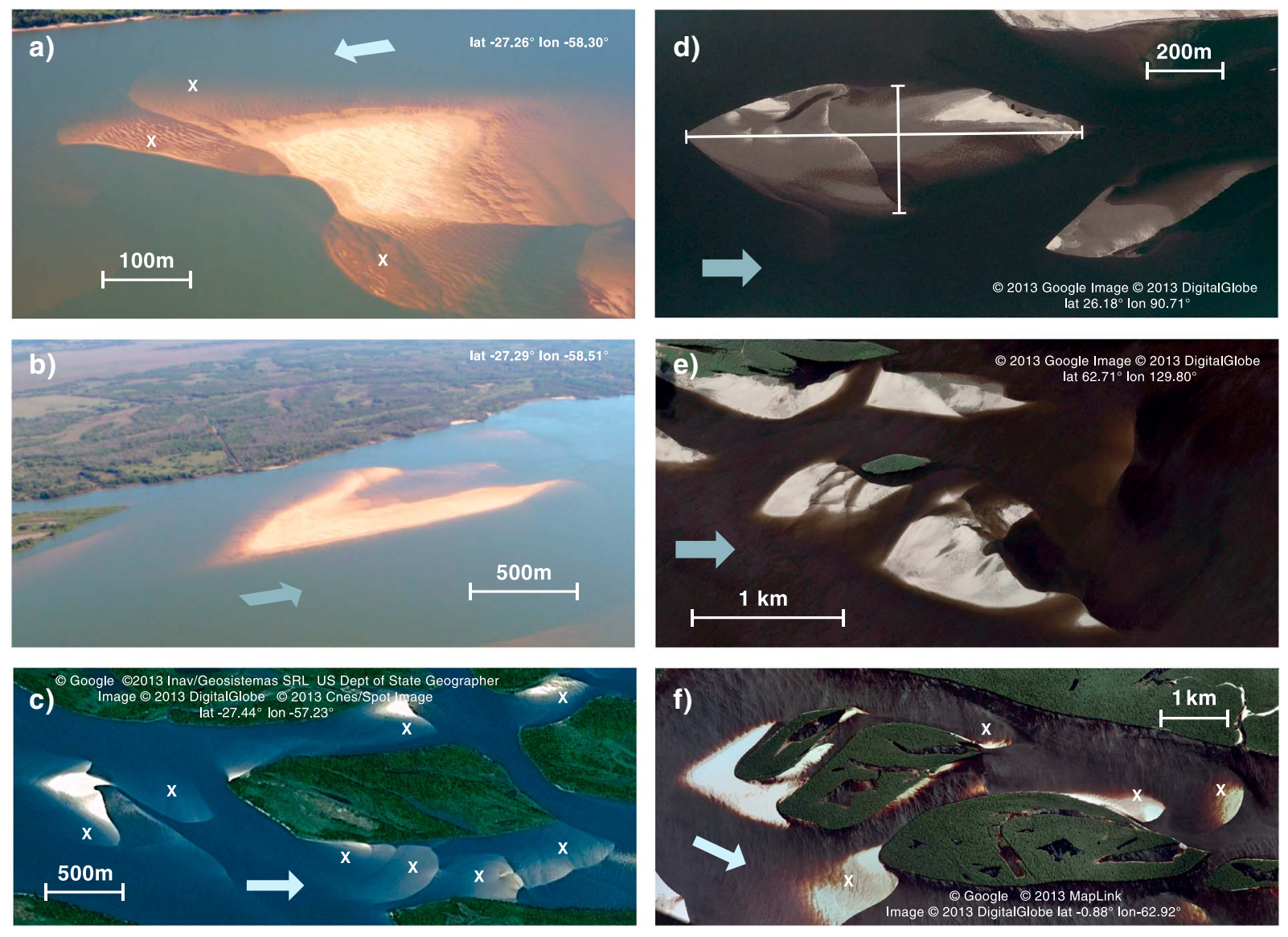

Figure 2. Examples of unit bars (labeled "X"), compound bars, and vegetated islands in selected large anabranching sand bed rivers: $(\mathrm{a}-\mathrm{c})$ the Paraná, Argentina, (d) the Brahmaputra, India, (e) the Lena, Russia, and (f) the Negro, Brazil. Arrows indicate flow direction. Figures $2 \mathrm{c}-2 \mathrm{f}$ acquired from Google Earth.

et al., 1996; Ashworth et al., 2000; Latrubesse and Franzinelli, 2002] have identified the main morphological elements of large bars and islands and have developed conceptual models of bar evolution. However, understanding of bar and island morphodynamics is limited by the difficulties of obtaining data quantifying flow, sediment transport, and bathymetric change over time scales relevant to bar formation [Amsler et al., 2005]. Moreover, it remains unclear if large rivers differ significantly from smaller channels, for which process understanding is better. For example, while unit bars have been recognized as the fundamental building blocks of compound bars in smaller sand-bed rivers [Sambrook Smith et al., 2006; Horn et al., 2012], studies of large anabranching rivers have suggested that unit bars may be less common [Ashworth and Lewin, 2012] or may play a less significant role in mid-channel bar construction [Ashworth et al., 2000]. However, this hypothesis remains untested, and some researchers have attributed the apparent lack of unit bars at high flow in large rivers to the difficulty of making observations in the presence of turbid water [Bridge and Lunt, 2006].

[5] Numerical models offer a potential tool for addressing these issues, not least because they provide a framework for integrating understanding of flow, sediment transport, and channel evolution over long time periods. Reduced-complexity models that neglect much of the physics governing flow and sediment transport have been applied to simulate the evolution of braided channels [e.g., Murray and Paola, 1994; Coulthard et al., 2007; Thomas et al., 2007] and shown to yield accurate predictions of flow characteristics in large anabranching rivers [Nicholas et al., 2012]. However, channel morphology simulated by such models can be unrealistic and highly sensitive to model grid resolution [Doeschl-Wilson and Ashmore, 2005; Nicholas and Quine, 2007], due to their neglect of momentum conservation, and the resulting implications for modeling spatial gradients in flow and sediment transport fields.

[6] Comparatively few attempts have been made to simulate multithread river evolution using physics-based numerical models. Two-dimensional approaches that combine the shallow water equations with sediment transport relationships have been applied to model patterns of erosion and deposition within large braided sand-bed rivers over periods of days to weeks [Olesen and Tjerry, 2002; Wang et al., 2008; Xia et al., 2010]. Such applications are initialized using surveyed river bathymetry and typically simulate relatively minor changes in bed morphology due to the short time periods under consideration. Consequently, they do not provide a basis for assessing a model's ability to generate realistic river morphology, where this has not been imposed as an initial condition. Several researchers have adopted an alternative approach in which models are initialized using a straight channel with a constant bed slope and a small initial bed perturbation and then run to simulate the evolution of river 
morphology [Enggrob and Tjerry, 1999; McArdell and Faeh, 2001; Jang and Shimizu, 2005; Crosato and Saleh, 2010; Wang et al., 2010]. Where such models have been evaluated using data collected in laboratory flume studies, they have shown considerable potential for simulating braided stream morphodynamics [Jang and Shimizu, 2005]. However, the ability of physics-based models to provide a realistic representation of bar and island morphodynamics in large, braided or anabranching rivers has yet to be demonstrated. This may reflect limitations in current understanding of fundamental processes, or a failure to combine the relevant processes within a single physics-based model [Kleinhans, 2010].

[7] The aim of this paper is to address the gaps in understanding highlighted above using a new model of large river morphodynamics: HSTAR (Hydrodynamics and Sediment Transport in Alluvial Rivers). Our objectives are to (i) assess the feasibility of simulating the evolution of large anabranching rivers over centennial time scales; (ii) examine model sensitivity to grid resolution, boundary conditions, morphodynamic scaling, and key aspects of process parameterization; (iii) establish the physical realism of simulated river morphology and bar and island morphodynamics; (iv) investigate the role of discharge variability, bank strength, and vegetation as controls on channel morphology; and (v) provide insight into the controls on unit bar frequency and styles of channel evolution in large sand-bed rivers.

\section{Numerical Modeling}

[8] The numerical model used in this study is described below in section 2.1. Following this, the design of the numerical simulations is outlined, and the model setup, boundary conditions, and parameter values are summarized (in section 2.2). Section 2.3 outlines the metrics used to quantify and evaluate the simulated channel morphology.

\subsection{Morphodynamic Model Description}

[9] HSTAR solves the two-dimensional, depth-averaged shallow water equations written in conservative form. Model equations are solved on a structured grid (resolution $\Delta x, \Delta y$ ) within which each grid cell is defined as either active river bed or floodplain (including vegetated islands). The conservation of mass and momentum equations solved by the model are expressed as:

$$
\begin{gathered}
\frac{\partial h}{\partial t}+\frac{\partial q_{x}}{\partial x}+\frac{\partial q_{y}}{\partial y}=0 \\
\frac{\partial q_{x}}{\partial t}+\frac{\partial\left(q_{x}^{2} / h\right)}{\partial x}+\frac{\partial\left(q_{x} q_{y} / h\right)}{\partial y}+\frac{g}{2} \frac{\partial\left(h^{2}\right)}{\partial x}+g h \frac{\partial z}{\partial x} \\
-\frac{1}{\rho} \frac{\partial\left(h \tau_{x y}\right)}{\partial y}-\frac{1}{\rho} \frac{\partial\left(h \tau_{x x}\right)}{\partial x}+\frac{\tau_{b x}}{\rho}-F_{S x}=0 \\
\frac{\partial q_{y}}{\partial t}+\frac{\partial\left(q_{y}^{2} / h\right)}{\partial y}+\frac{\partial\left(q_{x} q_{y} / h\right)}{\partial x}+\frac{g}{2} \frac{\partial\left(h^{2}\right)}{\partial y}+g h \frac{\partial z}{\partial y} \\
-\frac{1}{\rho} \frac{\partial\left(h \tau_{y x}\right)}{\partial x}-\frac{1}{\rho} \frac{\partial\left(h \tau_{y y}\right)}{\partial y}+\frac{\tau_{b y}}{\rho}-F_{S y}=0
\end{gathered}
$$

where $h$ is flow depth; $t$ is time; $q_{x}$ and $q_{y}$ are unit discharge in the $x$ and $y$ directions; $g$ is acceleration due to gravity; $\rho$ is fluid density; $z$ is bed elevation; $\tau_{x x}, \tau_{y y}, \tau_{x y}$, and $\tau_{y x}$ are turbulent stresses; $\tau_{b x}$ and $\tau_{b y}$ are bed shear stresses in the $x$ and $y$ directions; and $F_{S x}$ and $F_{S y}$ are stresses resulting from the effects of secondary flow. Turbulent stresses are treated using the Boussinesq approximation combined with a zero-order eddy viscosity model [Begnudelli et al., 2010]:

$$
\begin{aligned}
\tau_{x x} & =2 \rho v_{t} \frac{\partial u}{\partial x} \\
\tau_{x y}=\tau_{y x} & =\rho v_{t}\left(\frac{\partial u}{\partial y}+\frac{\partial v}{\partial x}\right) \\
\tau_{y y} & =2 \rho v_{t} \frac{\partial v}{\partial y} \\
v_{t} & =0.07 U_{*} h
\end{aligned}
$$

where $u=q_{x} / h$ and $v=q_{y} / h$ are the depth-averaged velocities in the $x$ and $y$ directions, $v_{t}$ is the turbulent viscosity, and $U_{*}$ is the shear velocity, which is determined from the local bed shear stress. Bed shear stresses are modeled using a quadratic friction law:

$$
\begin{gathered}
\frac{\tau_{b x}}{\rho}=\frac{g}{(C h)^{2}} q_{x} \sqrt{q_{x}^{2}+q_{y}^{2}} \\
\frac{\tau_{b y}}{\rho}=\frac{g}{(C h)^{2}} q_{y} \sqrt{q_{x}^{2}+q_{y}^{2}}
\end{gathered}
$$

where $C$ is the Chezy friction coefficient, which can be treated as a constant or determined using the Colebrook-White equation:

$$
C=18 \log \left(\frac{12 h}{k_{s}}\right)
$$

where $k_{s}$ is a roughness length scale, which includes the effects of both grain and form roughness. In the current application, floodplain cells are assigned a constant Chezy roughness $\left(C_{f}=10 \mathrm{~m}^{0.5} \mathrm{~s}^{-1}\right)$, which is representative of forested surfaces [Straatsma and Baptist, 2008]; hence, variations in vegetation structure (and roughness) with surface age are neglected.

[10] The stress terms in the momentum equations (2a) and (2b) resulting from secondary currents are determined as a function of the intensity of spiral motion of the flow from the following expressions:

$$
\begin{gathered}
F_{S x}=\frac{\partial\left(h T_{x x}\right)}{\partial x}+\frac{\partial\left(h T_{x y}\right)}{\partial y} \\
F_{S y}=\frac{\partial\left(h T_{y x}\right)}{\partial x}+\frac{\partial\left(h T_{y y}\right)}{\partial y} \\
T_{x x}=-2 \beta u v \\
T_{y y}=2 \beta u v \\
T_{x y}=T_{y x}=\beta\left(u^{2}-v^{2}\right) \\
\beta=\left(5 \alpha-15.6 \alpha^{2}+37.5 \alpha^{3}\right) \frac{\Phi h}{|q|} \\
\alpha=\frac{\sqrt{g}}{\kappa C}
\end{gathered}
$$

where $|q|$ is the unit discharge magnitude, $\kappa$ is the von 
Karman constant, and $\Phi$ is the spiral motion intensity of the flow, which is related to the radius of curvature (see below). This approach to modeling the stresses associated with secondary flow is adopted within the commercial code Delft3D [Lesser et al., 2004; Kleinhans et al., 2008; Deltares, 2010]. It is less sophisticated than a full treatment of the dispersive stresses, which is sometimes implemented when simulating flow in high curvature bends in laboratory-scale channels [e.g., Duan, 2004; Begnudelli et al., 2010]. However, a full treatment of the dispersive stresses is not necessary where curvature is low [Duan, 2004], such as in large anabranching rivers where secondary circulation may be weak or absent [Parsons et al., 2007; Sandbach et al., 2012].

[11] The spiral motion intensity of the flow is derived by solving an advection-diffusion transport equation of the form [de Vriend, 1981; Wu and Wang, 2004]:

$$
\begin{array}{r}
\frac{\partial(h \Phi)}{\partial t}+\frac{\partial\left(q_{x} \Phi\right)}{\partial x}+\frac{\partial\left(q_{y} \Phi\right)}{\partial y}-\frac{\partial}{\partial x}\left(D_{H} h \frac{\partial \Phi}{\partial x}\right) \\
-\frac{\partial}{\partial y}\left(D_{H} h \frac{\partial \Phi}{\partial y}\right)+\frac{|q|}{L}\left(\Phi-\frac{|q|}{R}\right)=0
\end{array}
$$

where $R$ is the local streamline radius of curvature (determined from the depth-averaged velocity field), $D_{H}$ is the horizontal diffusivity, and $L$ is an adaption length scale, which is given by:

$$
L=\frac{(1-2 \alpha) h}{2 \kappa^{2} \alpha}
$$

[12] The final term on the left-hand side of (11) accounts for the adjustment of $\Phi$ toward the local equilibrium value $|q| / R$.

[13] Two sediment size fractions are represented by the model: one sand fraction and one silt fraction. The proportion of sediment in each size class is stored in a series of vertical layers within each grid cell. Vertical layer thickness is set at $1 \mathrm{~m}$ for the simulations reported herein, as in previous morphodynamic simulations of the river Rhine [e.g., Sloff and Mosselman, 2012]. The initial sand fraction is set at $100 \%$ for channel cells and $30 \%$ for floodplain cells (i.e., floodplain cells are initially composed of $70 \%$ silt). Over the course of simulations, the sand:silt ratio for individual cell layers evolves due to erosion and deposition processes. For simplicity, a constant bed porosity is assumed, independent of the silt/sand ratio in each layer. Sediment transport calculations differ between active bed cells and vegetated floodplain cells. For active river bed cells, total sand transport capacity $\left(q_{T}\right)$, which includes sand moved as bed load and suspended load, is determined using a form of the relation of Engelund and Hansen [1967]:

$$
q_{T}=\frac{0.05 \chi|U|^{5}}{\sqrt{g} C_{0}{ }^{3} \psi^{2} D}
$$

where $|U|$ is the depth-averaged velocity magnitude, $\psi$ is the sediment relative density, $D$ is the representative (median) sand diameter, $\chi$ is a parameter that accounts for the effect of the local bed slope, and which is defined below (see equation (21)), and $C_{0}$ is a roughness coefficient determined from equation (6) with $k_{s}=3 D_{90}=6 D$ (see section 4 for further discussion of this choice of transport formula). The Engelund-Hansen transport law has been used widely in morphodynamic modeling of fluvial, estuarine, and coastal settings [Marciano et al., 2005; van der Wegen et al., 2008; Kleinhans et al., 2008]. The total sand transport capacity in each grid cell is separated into two components to reflect the local availability of sandsized bed material. These components are the actual sand transport rate $\left(q_{S}\right)$ and an excess transport capacity $\left(q_{E}\right)$ :

$$
\begin{gathered}
q_{S}=p q_{T} \\
q_{E}=(1-p) q_{T}
\end{gathered}
$$

where $p$ is the proportion of sand in the bed and $(1-p)$ is the proportion of silt.

[14] The sand transport direction deviates from the mean flow direction (defined by $q_{x}, q_{y}$ ) due to the effects of secondary circulation [Stuiksma et al., 1985; Kleinhans et al., 2008]:

$$
\begin{gathered}
\theta=\arctan \left(\frac{q_{y}}{q_{x}}\right)-\arctan \left(\frac{\varepsilon A h}{R_{*}}\right) \\
A=\frac{2(1-\alpha)}{\kappa^{2}} \\
R_{*}=\frac{|q|}{\Phi}
\end{gathered}
$$

where $R *$ is the effective radius of curvature of the flow, which differs from the local streamline curvature $(R)$ and is determined from the spiral motion intensity $(\Phi)$. The parameter $\varepsilon$ varies between 0 and 1, depending upon the mode of sand transport (i.e., bed load versus suspension). To determine the value of $\varepsilon$, the sand load is separated into bed load and suspended load fractions ( $\xi$ and $1-\xi$, respectively) using the approach of van Rijn [1984]. The bed load fraction moves in the direction of the near bed flow $(\varepsilon=1)$. The net direction of transport for the suspended sand fraction $(1-\xi)$ lies between the direction of the mean flow $(\varepsilon=0)$ and that of the near-bed flow $(\varepsilon=1)$ and is determined by integrating functions for the primary flow, secondary flow, and sand concentration profile [van Rijn, 1984; Kalkwijk and Booij, 1986]. Sand transport rates in the $x$ and $y$ directions $\left(q_{S x}\right.$ and $q_{S y}$, respectively) are then determined from:

$$
\begin{aligned}
& q_{S x}=q_{S} \cos (\theta)+q *_{S x} \\
& q_{S y}=q_{S} \sin (\theta)+q *_{S y}
\end{aligned}
$$

where $q *_{S x}$ and $q_{* S y}$ are additional sand fluxes resulting from the effect of gravity acting on sand in motion on a sloping bed [Ikeda, 1982; Deltares, 2010] given by:

$$
\begin{gathered}
q *_{S x}=-q_{S} \sin (\theta)\left(\frac{\xi}{\lambda}\right) \frac{\partial z}{\partial n} \\
q *_{S y}=q_{S} \cos (\theta)\left(\frac{\xi}{\lambda}\right) \frac{\partial z}{\partial n}
\end{gathered}
$$

where $\partial z / \partial n$ is the bed slope normal to the sediment transport 
direction and the parameter $\lambda$ is defined using the expression of Talmon et al. [1995]:

$$
\frac{1}{\lambda}=\frac{k}{9(D / h)^{0.3} \sqrt{\tau^{*}}}
$$

where $\tau^{*}$ is the dimensionless shear stress and $k$ is a constant that takes a value in the range 1-2 [Talmon et al., 1995]. Sediment transport rates are also adjusted to account for the effect of the local bed slope parallel to the direction of sediment transport $(\partial z / \partial s)$, via the parameter $\chi$ in equation (13):

$$
\chi=1+\xi \frac{\partial z}{\partial s}
$$

[15] As in a number of morphodynamic models, bed slope effects are applied only to the bed load fraction of the sand load, because it is this component that is in contact with the bed [Olesen and Tjerry, 2002; Lesser et al., 2004].

[16] Transport of silt is modeled using a two-dimensional advection-diffusion equation:

$$
\begin{array}{r}
\frac{\partial(h \phi)}{\partial t}+\frac{\partial\left(q_{x} \phi\right)}{\partial x}+\frac{\partial\left(q_{y} \phi\right)}{\partial y}-\frac{\partial}{\partial x}\left(D_{H} h \frac{\partial \phi}{\partial x}\right) \\
-\frac{\partial}{\partial y}\left(D_{H} h \frac{\partial \phi}{\partial y}\right)+D_{R}-E_{R}-B_{R}=0
\end{array}
$$

where $\phi$ is the depth-averaged sediment concentration and $D_{R}, E_{R}$, and $B_{R}$ are source terms representing rates of deposition, erosion from the bed, and sediment supply from banks, respectively. The deposition rate is modeled using the Krone equation:

$$
D_{R}=\phi w_{S}\left(\frac{\tau_{C}-\tau_{b}}{\tau_{C}}\right)
$$

where $w_{S}$ is the particle-settling velocity, $\tau_{b}$ is the bed shear stress, and $\tau_{C}$ is the critical shear stress (above which no deposition occurs).

[17] The rate of silt erosion from the bed in river cells is determined as:

$$
E_{R}=\left|\frac{q_{E x}}{\Delta x}\right|+\left|\frac{q_{E y}}{\Delta y}\right|
$$

where $q_{E x}$ and $q_{E y}$ are the components of the excess transport capacity in the $x$ and $y$ directions (determined from equation (14b)). This approach is based on the assumption that the rate of erosion in active bed cells is set by the amount of material that must be entrained to satisfy the total sand transport capacity (defined by equation (13)) and that the fraction of silt stored in the bed is released into suspension when this erosion occurs. For the simulations reported herein, the silt content of river bed cells is very low except in slack water zones located in the lee of the bar head. The bank sediment supply term $\left(B_{R}\right)$ in equation (22) is determined from the silt-sized sediment fluxes delivered by lateral bank erosion, summed over all floodplain cells bordering the channel cell under consideration:

$$
B_{R}=\sum \frac{q_{B x}(1-p)}{\Delta x}+\sum \frac{q_{B y}(1-p)}{\Delta y}
$$

where $(1-p)$ is the silt fraction in the floodplain cells, and the bank erosion fluxes are calculated as:

$$
\begin{aligned}
& q_{B x}=E q_{T y} S_{x} \\
& q_{B y}=E q_{T x} S_{y}
\end{aligned}
$$

where $E$ is a dimensionless bank erodibility constant, $q_{T x}$ and $q_{T y}$ are the total sand transport capacities in the $x$ and $y$ directions, and $S_{x}$ and $S_{y}$ are the bank slopes.

[18] Net changes in bed elevation for active river bed cells are determined from the Exner mass balance relation:

$$
(1-\delta) \frac{\partial z}{\partial t}+M\left[\frac{\partial q_{S x}}{\partial x}+\frac{\partial q_{S y}}{\partial y}-\sum \frac{q_{B x} p}{\Delta x}-\sum \frac{q_{B y} p}{\Delta y}-D_{R}+E_{R}\right]=0
$$

where $\delta$ is the bed porosity. In this expression, $M$ is a morphological scaling factor that is used to accelerate the rate at which the bed evolves, effectively decoupling the hydrodynamic and morphodynamic time steps used in the model. This is a common modeling strategy [e.g., Lesser et al., 2004; Crosato et al., 2012], justified by the fact that the bed morphology evolves much more slowly than the hydrodynamic variables; hence, vertical changes in bed elevation during individual time steps remain very small. For most simulations reported herein, $M$ is set at a value of 200 . In effect, this means that a time step of $\sim 3 \mathrm{~s}$ in the hydrodynamic model is equivalent to $\sim 10 \mathrm{~min}$ of real time in the context of sediment transport and channel change. This approach is discussed below in the context of model sensitivity to $M$ and choice of sediment transport relation. The third and fourth terms inside the square brackets in (27) represent the sand fluxes delivered by lateral bank erosion, summed over all floodplain cells bordering the channel cell under consideration. Equivalent bank-derived silt fluxes are not included in (27) because this material is assumed to enter suspension (via the $B_{R}$ term in equation (22)). In addition to the changes in bed elevation calculated using equation (27), the sand fraction $(p)$ in each grid cell is updated based on the net changes in the depth of sand (the first four terms inside the square brackets of (27)) and net changes in the depth of silt (fifth and sixth terms). Sand transport rate and associated mass balance calculations are implemented here using a capacitybased approach, which assumes that the transport rate is in local equilibrium with the flow. This approach remains valid while the sand transport adaption length is less than several multiples of the grid resolution [Begnudelli et al., 2010]. This criterion was evaluated using the adaption length definition of Begnudelli et al. [2010] and was satisfied for all simulations reported herein.

[19] Floodplain cells are treated differently to river bed cells in that they cannot be eroded vertically, unless they experience velocities in excess of a critical value $\left(V_{c r}\right)$, when they are reactivated by vertical scour (as opposed to lateral bank erosion). Consequently, floodplain reworking occurs predominantly by lateral erosion, parameterized by equations 
(26a) and (26b) above. To prevent diffusion of topography and maintain distinct channel bank lines, bank erosion does not lead to a reduction in bank height when floodplain cells are eroded. Instead, the volume of material removed from the floodplain cell by bank erosion is recorded, and the floodplain cell is converted to a channel cell at the level of the channel bed in the bank adjacent cell once sufficient material has been removed to lower the floodplain to that level. Despite the simplicity of this bank erosion scheme, it has proven capable of simulating the development of high sinuosity meanders [Nicholas, 2013a]. Silt deposition is an important component of floodplain construction. Active channel cells are converted to floodplain cells when the maximum depth of inundation experienced over a specified time period $\left(T_{v e g}\right)$ does not exceed a given threshold depth $\left(h_{c r}\right)$. Low $T_{v e g}$ and high $h_{c r}$ values promote rapid vegetation colonization. This representation of floodplain development and bank erosion aims to capture the first-order controls on channel evolution and is simple in order to avoid over-parameterization of processes.

[20] Model equations are solved by explicit time integration using a finite volume scheme in which all variables are stored at the cell centers. The solution of fluid mass and momentum equations utilizes a higher-order Godunov scheme. Such schemes are commonly used to solve the shallow water equations in a range of applications including the simulation of within-channel flows, floodplain inundation, and dam-break floods [Fraccarollo and Toro, 1995; Mingham and Causon, 1998; Liang et al., 2008]. Mass and momentum fluxes are computed using the Hartex-Lax-Van Leer approximate Riemann solver [Harten et al., 1983]. Second-order accuracy in time and space is achieved using a predictor-corrector scheme and the montone upwind scheme for conservation laws approach to variable reconstruction [van Leer, 1979]. Spurious oscillations in the solution domain are prevented using the double minmod limiter, which has been recommended because of its neutral dissipation properties [Sanders and Bradford, 2006]. The model hydrodynamic time step $(\Delta t)$ is defined to satisfy the Courant-Friedrichs-Lewy stability criterion. Validation of the hydrodynamic model in a large sand-bed river (the Rio Paraná, Argentina) is described elsewhere [Nicholas et al., 2012]. This study focuses on the simulation of river morphodynamics. The model outlined above is parallelized using a combination of openMP and MPI, and all simulations reported herein took approximately 2 weeks to complete using 12 cores on a SGI Altix ICE 8200 system with $2.8 \mathrm{GHz}$ Intel Westmere dual hexcore nodes. The main flow and/ or sediment transport equations used in HSTAR are similar to those used in a number of other two-dimensional morphodynamic models [e.g., Enggrob and Tjerry, 1999; Lesser et al., 2004; Jang and Shimizu, 2005; Kleinhans et al., 2008; Crosato and Saleh, 2010; Wang et al., 2010]. The key differences between HSTAR and these alternative models are in the simple two-fraction sediment transport approach adopted here, the treatments of bank erosion and bar conversion to floodplain by vegetation, and the numerics of the hydrodynamic finite volume scheme.

\subsection{Numerical Simulations}

[21] Numerical simulations were conducted to study the evolution of large anabranching sand-bed rivers over periods of several hundred years. All simulations used the same initial conditions: a straight channel, $2.4 \mathrm{~km}$ (60 grid cells) wide and $12 \mathrm{~m}$ deep, having a constant slope $(S)$ with small $( \pm 0.1 \mathrm{~m})$ white noise elevation perturbations. Trial simulations confirmed that qualitatively, styles of river evolution are independent of initial channel width, although narrower initial widths promoted greater initial channel widening, as might be expected. Boundary conditions consisted of a series of inflow hydrographs and a perturbation to the inlet bathymetry (both described below). Initial channel depth was set so that peak flows remain in-bank. However, vegetated islands that form during simulations as the channel widens are inundated during peak flows. All simulations were carried out using a model domain $50 \mathrm{~km}$ long by $16 \mathrm{~km}$ wide. In the default model setup, this was composed of $625 \times 400$ cells, each measuring $80 \mathrm{~m}$ long by $40 \mathrm{~m}$ wide. This cell aspect ratio $(\Delta x: \Delta y)$ provides the optimal balance between model efficiency and resolution, because it enables the use of larger model time steps (controlled predominantly by $\Delta x$ ), while maintaining the capability to resolve finer bars and channels in the cross-stream direction. Additional model runs were conducted for a subset of simulations using different cell sizes (including $60 \mathrm{~m}$ by $30 \mathrm{~m}$ and $60 \mathrm{~m}$ by $60 \mathrm{~m}$ ) to assess model sensitivity to grid resolution (see section 3.2).

[22] Inflow conditions consisted of a series of sinewave hydrographs with a minimum discharge of $10,000 \mathrm{~m}^{3} \mathrm{~s}^{-1}$ and peak discharges that varied from 15,000 to $30,000 \mathrm{~m}^{3}$ $\mathrm{s}^{-1}$ between individual events. The magnitude of this discharge is not unreasonable given that the world's largest rivers are usually associated with a mean annual discharge greater than $10,000 \mathrm{~m}^{3} \mathrm{~s}^{-1}$ [Latrubesse, 2008] although the largest flows can peak at around 100,000 $\mathrm{m}^{3} \mathrm{~s}^{-1}$. Moreover, it is recognized that hydrograph shapes for natural rivers are more complex than the sinewave hydrograph used here and may vary substantially between rivers. However, the aim of this study is to investigate generic characteristics of river behavior for relatively simple boundary conditions, rather than to simulate specific hydrologic regimes. A sequence of floods with varying peak discharge was generated and applied in all simulations. In model simulations that used the default setup, each hydrograph lasted 3.65 days, which, for the default value of 200 used for $M$, is equivalent to 2 years of morphodynamic time (note that all times reported hereafter represent morphodynamic times scaled in this way). Trial simulations were conducted to establish that the short hydrograph duration did not lead to substantial attenuation of peak discharge along the model domain. The effective morphodynamic duration (e.g., 2 years) of individual events simulated here is likely more appropriate in large sand-bed rivers characterized by an annual hydrograph than in smaller channels that experience more frequent, shortduration events. Sand supply rates at the inlet to the model domain are assumed to be at capacity. Silt concentrations at the inlet $\left(\phi_{I N}\right)$ are held constant throughout simulations (i.e., they do not vary over the course of the hydrograph).

[23] In natural rivers and laboratory channels with low Froude numbers, meander bends and alluvial bars propagate predominantly in a downstream direction [Seminara, 1998, 2006; van Dijk et al, 2012]. Consequently, in numerical models, unless such bed disturbances are introduced at the model domain inlet, the channel morphology downstream of the inlet is likely to evolve toward a relatively static configuration [Defina, 2003; Federici and Seminara, 2003]. A perturbation was therefore introduced at the upstream 
domain boundary to mimic an effect similar to the migration of lateral bars or a meandering thalweg through the inlet and to encourage the development of a non-symmetrical channel. This was achieved by representing the inlet cross section as a laterally inclined plane with a maximum amplitude $\left(Z_{I N}\right)$ that tipped back and forth over time period $\left(T_{I N}\right)$. Appropriate values for these parameters can be estimated from the amplitude, wavelength, and migration rate of bed disturbances (bars and thalwegs) in large rivers. For example, in the case of the Rio Paraná, Argentina [Ramonell et al., 2002], typical thalweg wavelengths (approximately $10 \mathrm{~km}$ ) and migration rates $\left(100 \mathrm{~m} \mathrm{yr}^{-1}\right)$ imply $T_{I N}=100$ years. In contrast, typical compound bar lengths (approximately $2.5 \mathrm{~km}$ ) and migration rates $\left(125 \mathrm{~m} \mathrm{yr}^{-1}\right)$ imply $T_{I N}=20$ years. In the case of the Jamuna, Coleman [1969] reports sand wave (unit bar) lengths (approximately $1 \mathrm{~km}$ ) and migration rates $(50-200 \mathrm{~m}$ $\mathrm{d}^{-1}$ ) that imply $T_{I N}=5-20$ days. Consequently, appropriate values for $T_{I N}$ vary over a wide range (e.g., from $<1$ to 100 years). In contrast, all these features have typical amplitudes on the order of $10 \mathrm{~m}$. In the default model setup, values of $T_{I N}=40$ years and $Z_{I N}=10 \mathrm{~m}$ were used. The sensitivity of the model results to the amplitude and period of the inlet oscillation is examined in section 3.2 below.

\subsection{Metrics of Channel Morphology}

[24] Model results are described and evaluated using a set of simple quantitative metrics. The number of individual channels (separated by dry bars/islands) was determined for each cross section in the model domain (e.g., each row of grid cells). The average value of this metric for all sections in the model domain is termed the braid intensity (or braiding index) and varies with flow stage (see below). The total planform area of wet cells divided by the domain length is termed the water surface width. Simulated channel depths are examined by considering the mean depth, maximum depth, and 99th percentile of the depth distribution, for any given channel digital elevation model (DEM) and discharge. The full depth frequency distribution is also considered when comparing simulated channel morphology with bathymetric data from natural rivers. Bar and island shapes are quantified in terms of the lengths of their major and minor axes (see Figure 2d). These lengths were determined for simulated channels by identifying each individual bar or island as a group of adjacent dry pixels that is entirely surrounded by water. The major axis was determined as the longest straight line that could be drawn on the bar/island. Note that this implies nothing about the orientation of the major axis, and it was not assumed that the major axis was aligned with the grid axes. Typically, the major axis is aligned with the mean flow on either side of the bar. The minor axis was then determined as the longest line perpendicular to the major axis with start and end points on the bar/island. This definition allows the minor axis to cross a topographic low that contains water (e.g., a slackwater zone between the limbs that typically extend downstream of the bar head) and is similar to that adopted by other researchers who have quantified midchannel bar shape in large rivers [Orfeo and Stevaux, 2002; Sambrook Smith et al., 2005; Kelly, 2006]. Bar shape (denoted by $\Omega$ ) is quantified here in terms of the ratio of major to minor axes lengths. The terms bar length and width are used interchangeably with major and minor axis lengths, respectively. In order to compare bar lengths for rivers of different sizes with model output, bar lengths are made dimensionless by dividing the major axis length by the mean width of all individual channels $(\langle W\rangle)$ within a reach. Data required for model evaluation were generated by digitizing bars and islands in several large sand-bed rivers. The rivers chosen for this analysis were the middle Paraná (mean annual discharge $\sim 17,000 \mathrm{~m}^{3} \mathrm{~s}^{-1}$ ), the Japurá (mean annual discharge $\sim 14,000 \mathrm{~m}^{3} \mathrm{~s}^{-1}$ ), and the Jamuna (mean annual discharge $\sim 21,000 \mathrm{~m}^{3} \mathrm{~s}^{-1}$ ). These rivers were selected because of their contrasting planform morphology (see Figure 1). Further details on their geomorphic characteristics are summarized elsewhere [Latrubesse, 2008]. Data for the Paraná were obtained from satellite images in which sandbars were visible (i.e., at low water). At moderate to high stages in this river, sandbars are typically submerged, but vegetated islands remain predominantly dry; hence, island shape changes little until overbank flows occur. In contrast, bar and island dimensions in the Jamuna depend strongly on flow stage [cf. Ashworth and Lewin, 2012, Figures 12b and $12 \mathrm{c}$. Consequently, distributions of bar and island shape were derived separately for low (February), intermediate (November), and high (September) stage conditions for the Jamuna. In the case of the Japurá River, only island shape is considered because few distinct sandbars are visible in satellite images (see Figure 1b).

\section{Results}

[25] Model results are presented below in five stages. First, results are shown for a single simulation based on the default model parameterization (see section 3.1), in order to outline generic aspects of model behavior and to provide a baseline for comparison with subsequent simulations. Second, model sensitivity to grid resolution, morphodynamic scaling, inlet boundary conditions, and process parameterization is examined. Third, the role of discharge variability, bank strength, and vegetation as controls on channel morphology and its evolution is considered. Fourth, the statistical characteristics of modeled channel morphology are compared with data from anabranching rivers characterized by differences in planform pattern and rates of morphological change. Finally, mechanisms and styles of simulated bar and island evolution are examined in more detail and compared with observations of channel change in large anabranching rivers.

\subsection{Simulated Channel Evolution}

[26] Typical values of longitudinal slope $(S)$ and median bed sediment diameter $(D)$ for large anabranching sand-bed rivers are in the range $S=1$ to $10 \mathrm{~cm} \mathrm{~km}^{-1}$ and $D=0.2$ to $0.5 \mathrm{~mm}$ [Latrubesse, 2008]. In the default model setup, values of $S=5 \mathrm{~cm} \mathrm{~km}^{-1}$ and $D=0.4 \mathrm{~mm}$ were used. These values ensure that the adaption length criterion, outlined above, is satisfied. Results from a series of model runs are presented below and compared with a baseline simulation for which the following parameter values were used: $C=55 \mathrm{~m}^{1 / 2} \mathrm{~s}^{-1}, T_{\text {veg }}=10$ years, $H_{c r}=0.1 \mathrm{~m}, E=3, k=2$, $M=200, Z_{I N}=10 \mathrm{~m}, \mathrm{~T}_{I N}=40$ years, $\phi_{I N}=150 \mathrm{mg} \mathrm{L}^{-1}$, and $w_{S}=0.0002 \mathrm{~m} \mathrm{~s}^{-1}$. The value of the parameter $k$ is based on the analysis of Talmon et al. [1995] and on recognition that in large sand-bed rivers, a substantial fraction of the sand load is transported in suspension [Amsler et al., 2007].

[27] Figure 3 illustrates channel morphology at selected points in time over the 530 year period of the baseline 


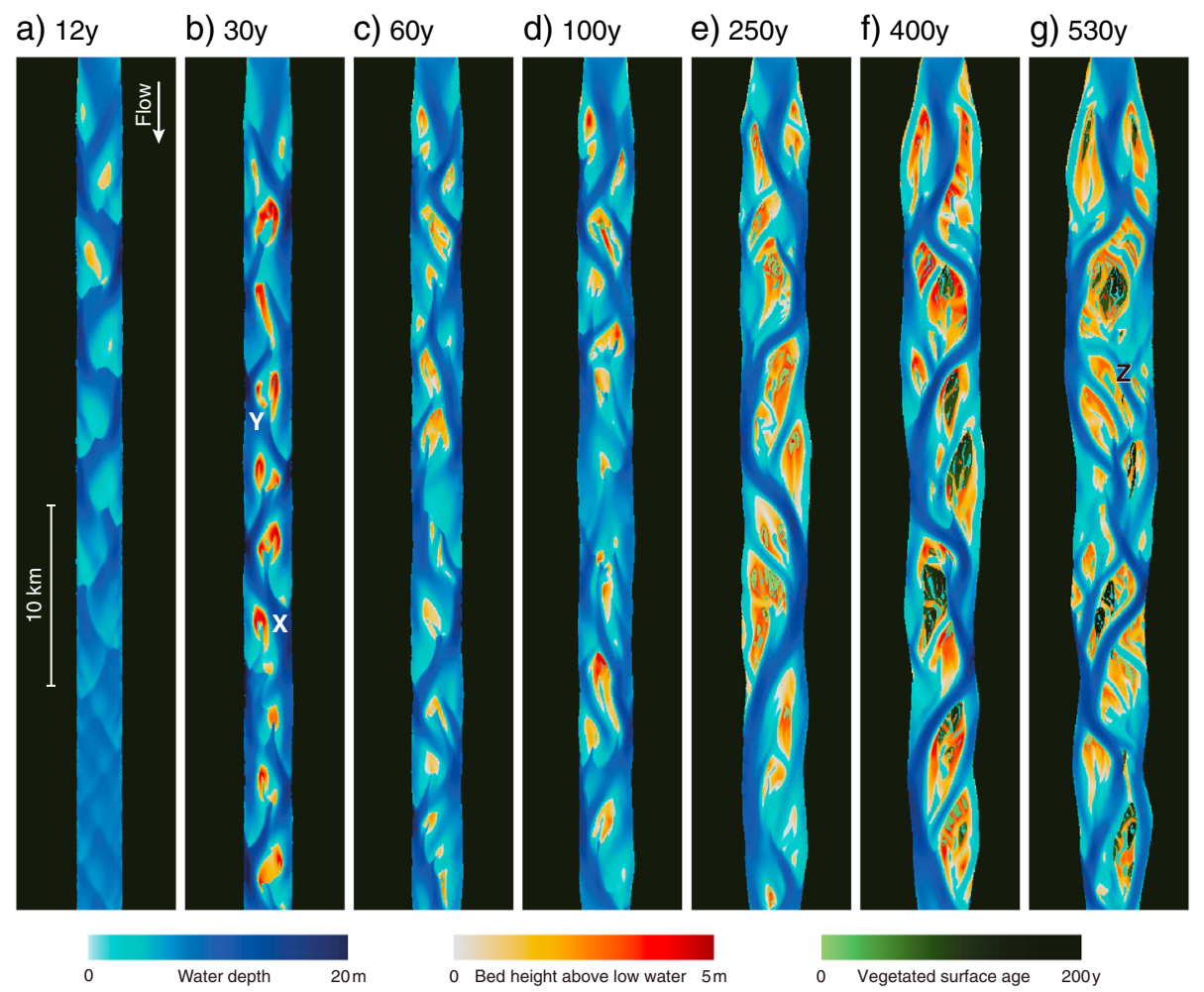

Figure 3. Sequence of channel evolution at seven points in time (indicated above each panel) during the baseline model simulation. Labels $\mathrm{X}, \mathrm{Y}$, and $\mathrm{Z}$ indicate locations referred to in the text. The scale bar for vegetated surface age is truncated to show a maximum age of 200 years. All images show low flow conditions (a discharge of $10,000 \mathrm{~m}^{3} \mathrm{~s}^{-1}$ ).

simulation that used the default model setup. The simulation duration reflects both the time scale over which the channel morphology approaches a state of equilibrium, and also a practical constraint imposed by available computational resources. It is also worth noting that few natural systems experience steady hydrological and sediment supply regimes over such extended time periods; hence, simulations should not be interpreted as representative of natural channel evolution over such time scales. Figure 4 shows the time series of peak discharge and the evolution of channel width, depth, and braid intensity for this simulation. Initial development of bed topography is associated with downstream propagation of alternate bar complexes (Figure 3a). These are promoted by the transverse bed gradient at the domain inlet, which encourages deposition downstream of the inlet thalweg, and lateral topographic forcing of flow to the opposite bank, leading to the development of a meandering thalweg. This phenomenon is similar to that observed in laboratory experiments [Fujita, 1989; Fukuoka, 1989; Lanzoni, 2000] and associated numerical modeling [Defina, 2003; Bernini et al., 2006]. However, in the simulations reported herein, lateral shoals are associated with flow divergence and become detached from the channel banks by chute cutoff [cf. Ashmore, 1982]. Individual shoals then form midchannel bars, while flow divergence at the bar head drives the generation of new sediment lobes (unit bars) that also propagate downstream and may initiate further shoaling and bar development (e.g., upstream of label X in Figure 3b). Small amplitude bed forms (unit bars) also develop throughout the channel as a result of the growth of perturbations in the initial bed topography (see downstream end of Figure 3a). These bed forms grow as they migrate downstream, but are quickly overtaken by the disturbances that propagate from the domain inlet. Model sensitivity to the inlet boundary condition is discussed further in section 3.2 below.

[28] The initial stage of channel evolution results in a sequence of evenly spaced midchannel bars separated by a distance equal to half the wavelength of the sinuous thalweg. These bars are typically characterized by limbs that extend downstream on either side of the bar head, sometimes with one limb outgrowing the other as the bar becomes asymmetric over time. Concentration of flow within the topographic low between these limbs can promote bar dissection at times of peak discharge (e.g., at label Y in Figure 3b). This initial sequence of bar evolution is similar to that observed on the Jamuna [Ashworth et al., 2000, Figure 11, stages 3-6]. These regularly spaced bars are conveyed downstream and eroded within approximately 10-15 years. Thereafter, bar sizes, shapes, and locations become increasingly variable, and the simulation enters a phase in which bars are highly mobile and transitory features (Figures $3 \mathrm{c}$ and $3 \mathrm{~d}$ ). Bar height varies substantially in space and time as a function of bar age and the magnitude of recent discharge peaks, which determine maximum water levels that set a limit on bar top aggradation. Median bar length at low flow tends to increase over time (from approximately $1.9 \mathrm{~km}$ in the first 200 years of the simulation to approximately $2.65 \mathrm{~km}$ over the subsequent 330 years), in part due to channel widening by bank erosion (Figure $4 \mathrm{~b}$ ). Large vegetated islands develop from approximately 250 years onward, following a period of frequent high 

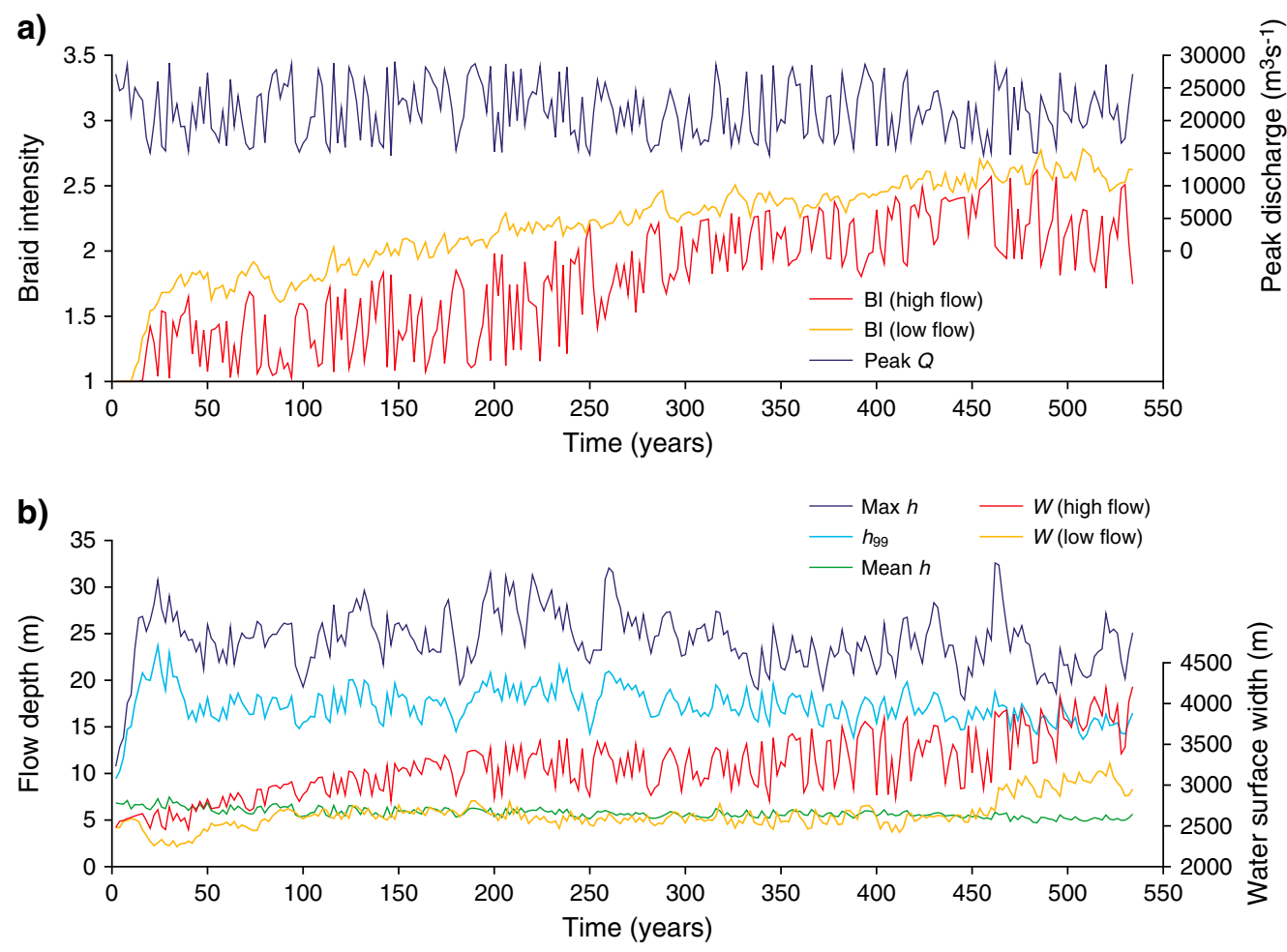

Figure 4. Temporal changes in key model variables over the course of the baseline simulation shows (a) the time series of peak discharge for each flood event, and the braid intensity of the simulated channel at low flow $\left(10,000 \mathrm{~m}^{3} \mathrm{~s}^{-1}\right)$ and high flow (discharge indicated by flood peak time series) and (b) the time series of water surface width at low and high flows, and maximum, mean, and 99th percentile of flow depth.

flows that promote bar aggradation. The subsequent 60 year period is characterized by lower peak flows, encouraging vegetation establishment on emergent bar surfaces. Vegetated islands provide stable nuclei around which more mobile unit bars and compound bars aggregate (Figures $3 \mathrm{f}$ and $3 \mathrm{~g}$ ). This creates semipermanent (life spans of several hundred years) stable islands, leading to zones of reduced channel dynamism. Slow but progressive erosion of vegetated islands may ultimately promote a return to a more dynamic state characterized by smaller and more mobile unvegetated bars (e.g., near label $\mathrm{Z}$ in Figure $3 \mathrm{~g}$ ).

[29] Braid intensity at low flow increases progressively over the simulation. High flow braid intensity is lower and more variable, due to variations in peak discharge. Braid intensity for the highest discharges remains low until after the establishment of large vegetated islands at approximately 250 years (Figure 4a) and declines after approximately 460 years. The latter reflects a period of island reworking (described above) that also promotes an increase in water surface width for all discharges (Figure 4b). This occurs after a period of approximately 200 years during which water surface widths were relatively steady (for any given discharge). The degree to which simulated rates and styles of bar development and channel evolution are consistent with those observed in natural rivers is discussed in more detail in section 3.5 .

\subsection{Model Sensitivity}

[30] A series of model runs were carried out to assess the sensitivity of simulated channel morphology to changes in the model grid resolution, morphodynamic scaling factor $(M)$, inlet boundary conditions, and the parameterization of bed roughness and sediment transport. Model runs conducted using finer grid resolutions or lower morphodynamic scaling factors than those used in the baseline simulation are more computationally intensive and are typically of shorter duration than the baseline run described in section 3.1. In such cases, simulation results are compared after periods of between 150 and 320 years. Sensitivity experiments were conducted for the baseline model parameterization and for cases involving higher bank erodibility $(E=10)$.

[31] Figures 5a-5c show channel morphology after 250 years for three simulations that use the baseline parameterization, but with $E=10$. These model runs examine the effects of varying grid cell resolution and aspect ratio. All three simulations produce braided channels characterized by dynamic bars that are large and relatively free of vegetation (due to the higher value of $E$ relative to the baseline model run). Table 1 summarizes selected metrics of channel morphology for these simulations (values have been averaged over the periods from 100 to 150 years and 200 to 250 years). The main influence of grid resolution is on bar size, because grid resolution sets a limit on the smallest features that can be resolved. Consequently, the simulation that uses the finest grid $(60 \mathrm{~m} \times 30 \mathrm{~m}$; Figure $5 \mathrm{~b})$ is characterized by the smallest bars and the highest density of bars $(N)$. Moreover, both average and maximum bar sizes tend to be smaller for this model run. Channel widths and braid intensities are similar for all simulations. Braid intensity is lowest where $\Delta x=\Delta y$ (Figure 5c) because of the coarse lateral grid 

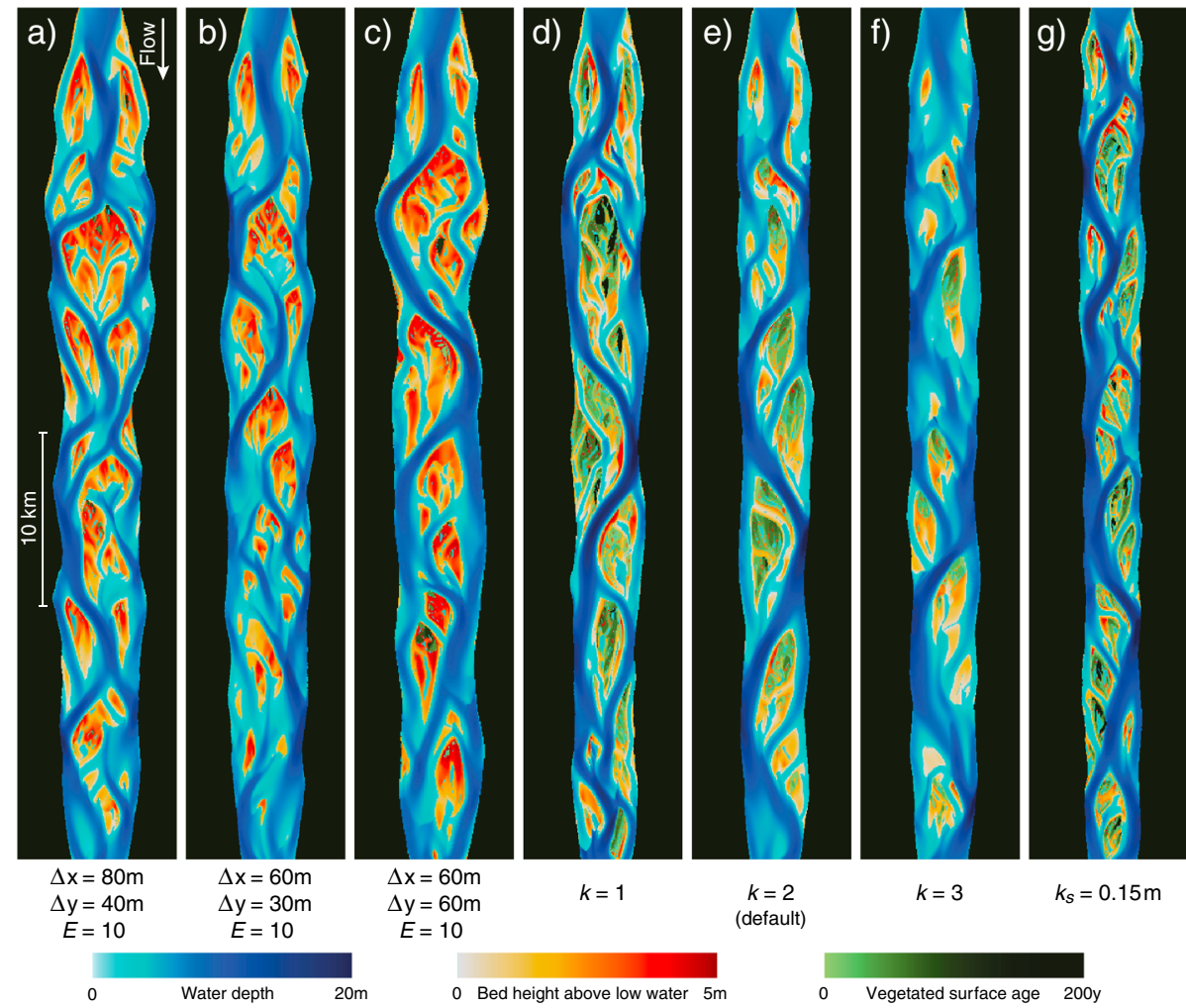

Figure 5. Simulated channel morphology for seven tests of model sensitivity. (a-c) Show the effects of varying model grid resolution. Channel morphology is shown after 250 years for three simulations that use the baseline model parameterization, but with $E=10$. Grid resolutions are (a) $\Delta x=80 \mathrm{~m}, \Delta y=40 \mathrm{~m}$; (b) $\Delta x=60 \mathrm{~m}, \Delta y=30 \mathrm{~m}$; and (c) $\Delta x=60 \mathrm{~m}, \Delta y=60 \mathrm{~m}$. (d-g) Show the effects of varying model process parameterizations. Channel morphology is shown after 320 years for four simulations that use the baseline simulation, but with (d) $k=1$ (in equation (20)); (e) $k=2$ (i.e., the baseline simulation); (f) $k=3$; and (g) $C$ defined by equation (6) with $k_{s}=0.15 \mathrm{~m}$. The scale bar for vegetated surface age is truncated to show a maximum age of 200 years. All images show low flow conditions (a discharge of $10,000 \mathrm{~m}^{3} \mathrm{~s}^{-1}$ ). Parameters that differ from those in the baseline model simulation are shown below each panel.

resolution $(60 \mathrm{~m})$, which limits the number of channels that can be resolved across a section. These results are typical of other time periods during these simulations and indicate that simulated channel morphology is weakly dependent on grid resolution. Importantly, bar shape $(\Omega)$ is largely independent of both grid resolution and aspect ratio $(\Delta x / \Delta y)$.

[32] Figures $5 \mathrm{~d}-5 \mathrm{~g}$ show channel morphology after 320 years for four simulations that examine the effects of changes in model process parameterization. Figure 5e shows results for a simulation that uses the baseline model parameterization, in which $k=2$ (see equation (20)). Figures $5 \mathrm{~d}$ and $5 \mathrm{f}$ use the same model setup, but with $k=1$ and $k=3$, respectively. The transition from Figure $5 \mathrm{~d}$ to $5 \mathrm{f}$ therefore illustrates the effect of an increase in the strength of sediment deflection by gravity in the direction of the transverse bed slope. This promotes enhanced sediment transport from bar tops toward channel thalwegs, leading to smaller bars, shallower channels, and a more discontinuous thalweg. At present, the value of $k$ is poorly constrained by field data, and the values used here are informed by the observations of Talmon et al. [1995]. The importance of gravitational deflection of bed load as a control on channel morphology is discussed in more detail below (see section 3.5).

Table 1. Influence of Grid Resolution $(\Delta x, \Delta y)$ on Channel Morphology

\begin{tabular}{|c|c|c|c|c|c|c|c|c|c|}
\hline$\Delta x^{\mathrm{a}}$ & $\Delta y^{\mathrm{a}}$ & Time $^{b}$ & $B I$ & $W$ & $L_{25}$ & $L_{75}$ & $N$ & $\Omega_{25}$ & $\Omega_{75}$ \\
\hline $80 \mathrm{~m}$ & $40 \mathrm{~m}$ & & 2.24 & $2.72 \mathrm{~km}$ & $1.59 \mathrm{~km}$ & $3.98 \mathrm{~km}$ & 0.40 & 2.27 & 3.39 \\
\hline $60 \mathrm{~m}$ & $30 \mathrm{~m}$ & $100-150$ years & 2.12 & $2.89 \mathrm{~km}$ & $0.88 \mathrm{~km}$ & $2.56 \mathrm{~km}$ & 0.55 & 2.11 & 3.51 \\
\hline $60 \mathrm{~m}$ & $60 \mathrm{~m}$ & & 1.93 & $2.84 \mathrm{~km}$ & $1.37 \mathrm{~km}$ & $3.80 \mathrm{~km}$ & 0.35 & 2.18 & 3.67 \\
\hline $80 \mathrm{~m}$ & $40 \mathrm{~m}$ & & 2.55 & $2.99 \mathrm{~km}$ & $1.47 \mathrm{~km}$ & $4.50 \mathrm{~km}$ & 0.48 & 2.27 & 3.59 \\
\hline $60 \mathrm{~m}$ & $30 \mathrm{~m}$ & $200-250$ years & 2.49 & $3.22 \mathrm{~km}$ & $1.13 \mathrm{~km}$ & $2.88 \mathrm{~km}$ & 0.63 & 2.00 & 3.42 \\
\hline $60 \mathrm{~m}$ & $60 \mathrm{~m}$ & & 2.26 & $2.94 \mathrm{~km}$ & $1.75 \mathrm{~km}$ & $4.74 \mathrm{~km}$ & 0.36 & 2.10 & 3.68 \\
\hline
\end{tabular}

\footnotetext{
${ }^{a}$ Results are shown for three simulations conducted using the baseline model parameterization (with $E=10$ ) and varying model grid resolutions.

${ }^{\mathrm{b}}$ Rows 2-4 and 5-7 report average morphology over the periods from 100 to 150 years and 200 to 250 years, respectively. Morphological parameters are braid intensity $(B I)$, water surface width $(W), 25$ th and 75th percentiles of bar major axis length $\left(L_{25}\right.$ and $\left.L_{75}\right)$, mean number of bars per km channel length $(N)$, and 25 th and 75 th percentiles of bar shape $\left(\Omega_{25}\right.$ and $\left.\Omega_{75}\right)$. All parameters are determined for low flow conditions.
} 


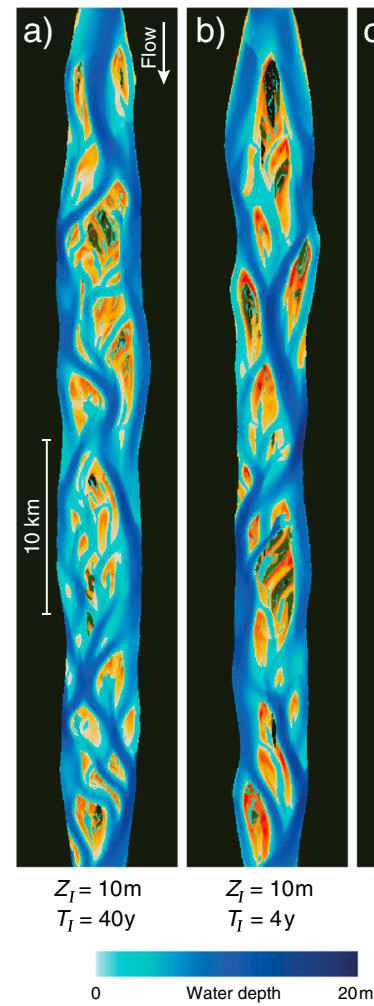

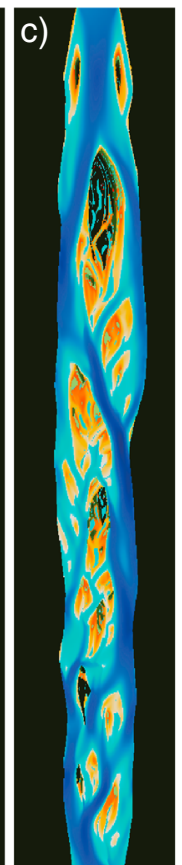

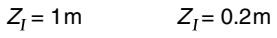

$T_{I}=40 y$

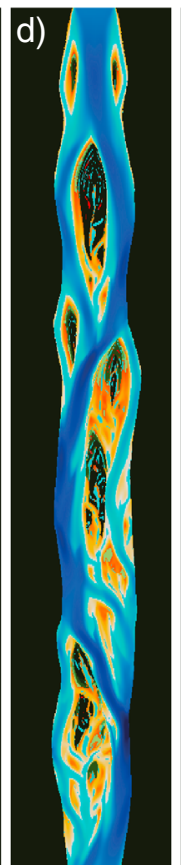

$Z_{I}=0.2 \mathrm{~m}$

$T_{I}=1 \mathrm{y}$

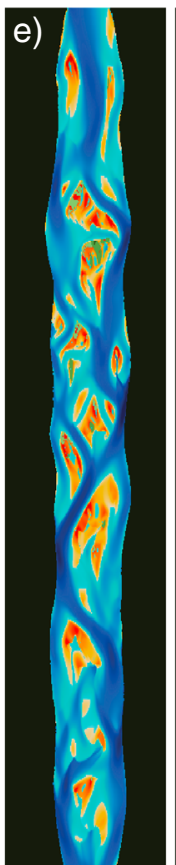

$M=200$

$E=10$

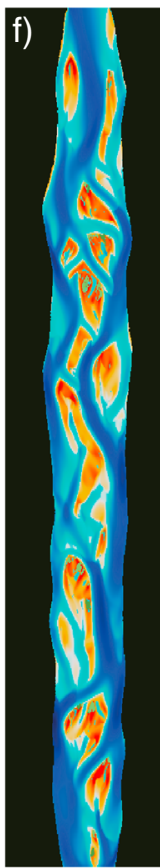

$M=100$ $E=10$

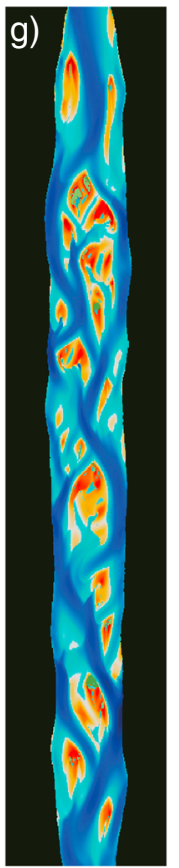

$M=50$

$E=10$

Figure 6. Simulated channel morphology for seven tests of model sensitivity. (a-d) Show the effects of varying model inlet boundary conditions (defined in terms of the parameters $Z_{I}$ and $T_{I}$ ). Channel morphology is shown after 530 years for four simulations: a replicate of the baseline simulation, with (a) $Z_{I}=10 \mathrm{~m}$ and $T_{I}=40$ years; (b) $Z_{I}=10 \mathrm{~m}$ and $T_{I}=4$ years; (c) $Z_{I}=1 \mathrm{~m}$ and $T_{I}=40$ years; and (d) $Z_{I}=0.2 \mathrm{~m}$ and $T_{I}=1$ year. $(\mathrm{e}-\mathrm{g})$ Show the effects of varying the morphodynamic scaling factor $(M)$. Channel morphology is shown after 150 years for three simulations that use the baseline model parameterization, but with $E=10$. The values of $M$ used are (e) $M=200$; (f) $M=100$; and (g) $M=50$. The scale bar for vegetated surface age is truncated to show a maximum age of 200 years. All images show low flow conditions (a discharge of $10,000 \mathrm{~m}^{3} \mathrm{~s}^{-1}$ ). Parameters that differ from those in the baseline model simulation are shown below each panel.

[33] Figure 5g shows the results for a simulation that uses the baseline parameterization, but with the Chezy coefficient used in bed shear calculations (equations (5a) and (5b)) defined using the Colebrook-White equation (6). A value of $k_{\mathrm{s}}=0.15 \mathrm{~m}$ is used here, which yields a value of $C=49 \mathrm{~m}^{1 / 2} \mathrm{~s}^{-1}$, for the mean flow depth in this simulation. This depth-dependent roughness formulation leads to an increase in velocity and sand transport capacity in deep areas of the channel relative to shallow areas. This encourages scouring of thalwegs and deposition on bar tops; hence, it has a similar effect on channel morphology to a reduction in $k$ (discussed above), although individual bars and islands in Figure $5 \mathrm{~g}$ tend to be smaller than in Figure 5d, and the braidplain width is narrower. Overall, model results illustrate that channel morphology is sensitive to the parameterization of bed roughness and the gravitational deflection of sediment in the direction of the local bed slope. However, model results are robust in the sense that bar shapes, and processes and styles of bar evolution (discussed further in sections 3.4 and 3.5) are consistent between simulations and are largely independent of model parameterizations. Consequently, generic insight into bar and island morphodynamics can be obtained without the need to calibrate these parameters precisely, although in order to apply the model to simulate a specific field prototype, rigorous calibration would be required.
[34] Figures 6a-6d show channel morphology after 530 years for four simulations that utilize contrasting inlet boundary conditions, but are identical to the baseline simulation in all other respects. In the baseline model run, the amplitude and period of the inlet oscillation are $Z_{I}=10 \mathrm{~m}$ and $T_{I}=40$ years, respectively. Results shown in Figure 6a are for a replicate of the baseline run that uses the same values of $Z_{I}$ and $T_{I}$, but a different discharge time series (with identical statistical properties). As expected, although the exact spatial distributions of bars and channels for this simulation and the baseline model run are different, overall, the channel morphology is similar, both visually and in terms of quantitative metrics. For example, low flow braid intensity over the final 20 years of the baseline simulation (shown in Figure 3g) ranges from 2.46 to 2.73 (mean of 2.56) compared to a range of 2.46 to 2.65 (mean of 2.58) for the simulation shown in Figure 6a. This provides an indication of the variability in simulation results that occurs independent of differences in model parameterization. For $Z_{I}=10 \mathrm{~m}$ and $T_{I}=4$ years (Figure $6 \mathrm{~b}$ ), the channel remains braided throughout the majority of the model domain, but a large island forms near the reach inlet. This is also the case where $Z_{I}=1 \mathrm{~m}$ and $T_{I}=40$ years (Figure 6c), although upstream of the island near the inlet, a pair of small stable islands also form on either side of the channel. This configuration is repeated in Figure 6d $\left(Z_{I}=0.2 \mathrm{~m}\right.$ and $T_{I}=1$ year), and there is also evidence that this 

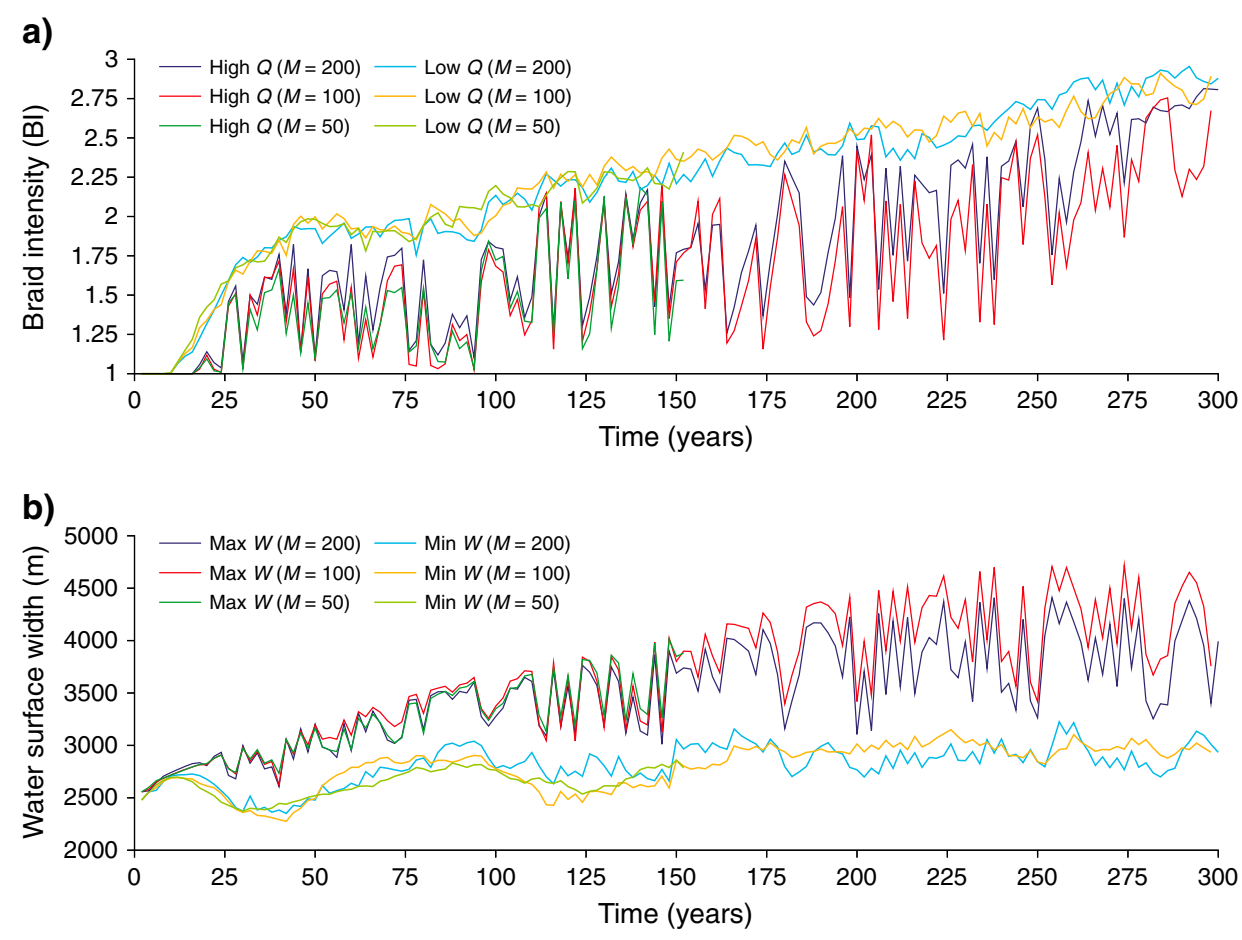

Figure 7. Temporal changes in (a) braid intensity at high and low flow and (b) water surface width at high and low flows, for model simulations conducted using different values of the morphological scaling factor $(M)$. Simulations correspond to those shown in Figures $6 \mathrm{e}$ to $6 \mathrm{~g}$ and were conducted for the baseline model parameterization, but with $E=10$. Simulation duration varies because of the greater computation resource required to implement the model for lower values of $M$.

simulation is characterized by fewer small bars and channels, and an increase in bar size and vegetation extent throughout the model domain. Mean low flow braid intensities over the final 20 years of the simulations shown in Figures $6 \mathrm{~b}-6 \mathrm{~d}$ are $2.27,2.29$, and 1.97, respectively (compared to 2.58 in Figure $6 \mathrm{a}$ ). However, in the downstream $70 \%$ of the model reach mean low flow braid intensities are higher $(2.34$ for the simulation in Figure $6 \mathrm{~b}$ and 2.60 for Figure $6 \mathrm{c}$ ). Overall, these results indicate that weaker inlet perturbations (e.g., lower values of $Z_{I}$ and/or $T_{I}$ ) promote more symmetrical (and potentially more stable) channel configurations near the inlet. However, the channel remains braided throughout the majority of the domain and there is no unequivocal evidence of model sensitivity to the inlet condition in the downstream $70 \%$ of the reach until both parameters are reduced substantially (as in Figure 6d). Moreover, typical values for bar and thalweg dimensions and migration rates in large sand bed rivers (discussed above) imply that values of $Z_{I}$ and $T_{I}$ in the order of those used in the baseline simulation are appropriate.

[35] Figures 6e-6g show channel morphology after 150 years for three simulations that use different values of the morphological scaling factor $(M)$. Other model parameter values and setup conditions are identical to those in the baseline simulation, but with $E=10$. Figures $7 \mathrm{a}$ and $7 \mathrm{~b}$ show changes in braid intensity and water surface width for these model runs. Simulated channel morphology after 150 years in the upstream $15-20 \%$ of the model domain is approximately identical for these three model runs. Because bed elevation disturbances propagate downstream, small differences between these model runs tend to grow through time and farther downstream. Despite this, the distribution of bars and channels in the downstream $80 \%$ of the model domain at 150 years is similar for different values of $M$, in terms of the number and size of bars. Moreover, differences in width and braid intensity for these simulations are relatively small (see Figure 7) and do not vary systematically with $M$. For example, for the period from 130 to 150 years (the final 20 years of the simulation conducted using $M=50$ ), mean low flow braid intensities for simulations shown in Figures $6 \mathrm{e}-6 \mathrm{~g}$ are $2.24,2.33$, and 2.25 , respectively. These results show that simulations conducted using different values of $M$ are not identical but that channel morphology develops along the same morphodynamic trajectory and at the same rate (i.e., channel width and braid intensity follow the same temporal trends). In addition, during the early stages of channel development (e.g., equivalent to stages a and b in Figure 3b), direct comparison between simulations is possible in terms of the evolution of specific bars. This illustrates that bar migration rates do not differ significantly as a function of $M$.

\subsection{Controls on Large River Morphology: Discharge, Bank Strength, and Vegetation}

[36] In order to examine the role of bank strength, vegetation, and discharge variability as controls on channel form in the numerical model, a matrix of 12 simulations was conducted using three values of the bank erodibility parameter $(E=1,3$, and 10), two parameterizations of vegetation that promote slow floodplain development $\left(T_{\text {veg }}=10\right.$ years, $\left.H_{c r}=0.1 \mathrm{~m}\right)$ and rapid floodplain development $\left(T_{\text {veg }}=6\right.$ years, $\left.H_{c r}=0.3 \mathrm{~m}\right)$, and two contrasting hydrological regimes. The latter consisted of first, a series of hydrographs with varying peak discharge, as in the baseline simulation, and second, a constant discharge of $22,500 \mathrm{~m}^{3} \mathrm{~s}^{-1}$ (equal to the average flood peak in the 


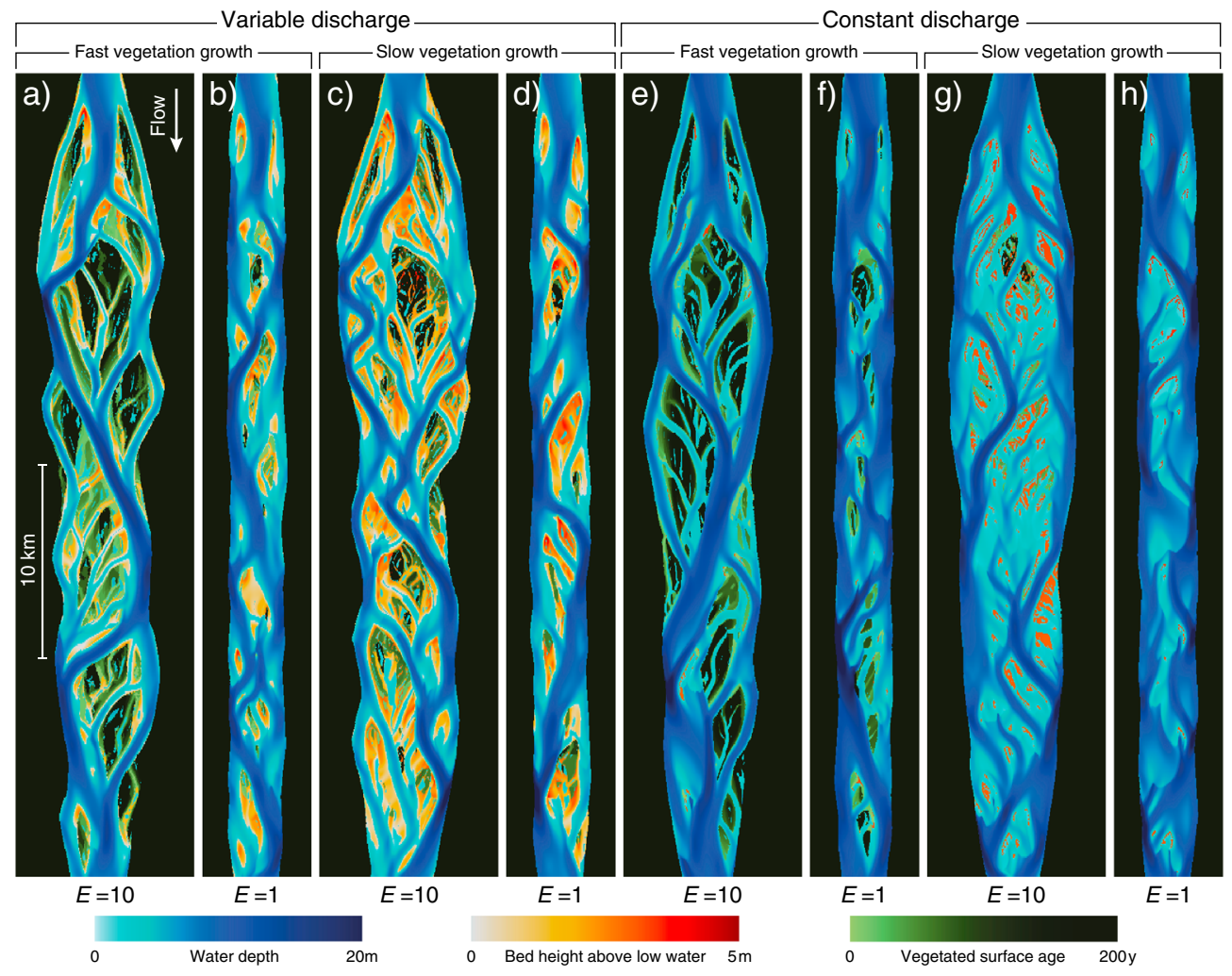

Figure 8. Simulated channel morphology after 500 years for model runs designed to investigate the effects of differences in bank erodibility, hydrologic regime and rate of vegetation establishment. (a-d) Model runs use the baseline flood series (shown in Figure 4a) and morphology is shown at low flow $\left(Q=10,000 \mathrm{~m}^{3} \mathrm{~s}^{-1}\right)$, whereas $(\mathrm{e}-\mathrm{h})$ simulations use a constant discharge of 22,500 $\mathrm{m}^{3} \mathrm{~s}^{-1}$. Runs a, c, e, and g use high bank erodibility $(E=10)$, whereas runs $\mathrm{b}, \mathrm{d}, \mathrm{f}$, and h use low bank erodibility $(E=1)$. In runs a, b, e, and f, vegetation establishment is rapid $\left(T_{v e g}=6\right.$ years, $\left.H_{c r}=0.3 \mathrm{~m}\right)$, whereas in runs $\mathrm{c}, \mathrm{d}, \mathrm{g}$, and h, vegetation establishment is slow $\left(T_{v e g}=10\right.$ years, $\left.H_{c r}=0.1 \mathrm{~m}\right)$. The scale bar for vegetated surface age is truncated to show a maximum age of 200 years.

simulations with varying discharge). Figure 8 shows the simulated river morphology for eight of these model runs after a period of 500 years. Table 2 summarizes the key metrics of channel form for these simulations.

[37] Model results illustrate the expected tendency for channel width and braid intensity to increase with bank erodibility (e.g., compare Figures 8c and 8d). This is the case for both discharge regimes considered and for both slow and rapid vegetation colonization. Despite the apparent differences in channel morphology evident in Figure 8, there is remarkable consistency in channel width and depth for simulations involving constant and variable discharge (i.e., when comparing metrics for simulations with the same bank erodibility and parameterization of vegetation colonization in Table 2). When banks are highly erodible $(E=10)$, constant discharge promotes higher braid intensity than variable discharge, particularly where vegetation is established rapidly (compare Figures $8 \mathrm{a}$ and 8e and see Table 2). In contrast, when banks are strong $(E=1)$, constant discharge promotes lower braid intensities than variable discharge, particularly where vegetation is slow to colonize (compare Figures $8 \mathrm{~d}$ and $8 \mathrm{~h}$ and see Table 2). Moreover, bars and islands generated under constant discharge tend to be small (Figures $8 \mathrm{f}-8 \mathrm{~h}$ ) except where banks are weak and vegetation develops rapidly (Figure 8e). These trends reflect two main controls on bar development. First, strong banks limit channel width, maintain high sediment transport rates, and restrict bar development, especially where vegetation is slow to stabilize bars. Second, water level sets the maximum height to which bars can aggrade. Consequently, variable discharge promotes bars that grow to the height of the largest floods, so that at lower water levels, the exposed bar extent is larger than where discharge does not vary. In the latter case, bar emergence is dependent on a drop in water level associated with local thalweg scour or bank erosion. As a result, where discharge is steady and bank erodibility is low, bars rarely emerge above the water (see Figure $8 \mathrm{~h}$ ) and vegetation establishment is restricted. Despite the relationship between discharge variability and bar height, topographic relief does not vary substantially or consistently between simulations. This may be because lower bar heights associated with constant discharge are compensated by greater maximum scour depths. By comparison, where discharge varies, scour pools tend to fill slightly (by $<2 \mathrm{~m}$ ) at low discharge, and maximum flow depths at high flow are approximately $10 \%$ lower than for simulations with constant discharge. The inability of bars to emerge and stabilize where discharge is constant and vegetation establishment is slow leads to a dynamic channel with a bed that is reworked rapidly, particularly where channels are narrow because bank erodibility is low. This tendency is indicated by 
NICHOLAS ET AL.: BAR AND ISLAND MORPHODYNAMICS IN MEGARIVERS

Table 2. Influence of Hydrologic Regime, Vegetation, and Bank Erodibility on Channel Morphology

\begin{tabular}{|c|c|c|c|c|c|c|c|c|c|c|c|c|}
\hline & \multicolumn{6}{|c|}{ Variable Discharge (Flood Hydrographs) ${ }^{\mathrm{a}}$} & \multicolumn{6}{|c|}{ Constant Discharge $\left(22,500 \mathrm{~m}^{3} \mathrm{~s}^{-1}\right)$} \\
\hline & \multicolumn{3}{|c|}{$\begin{array}{l}\text { Fast Vegetation } \\
\text { Establishment }\end{array}$} & \multicolumn{3}{|c|}{$\begin{array}{l}\text { Slow Vegetation } \\
\text { Establishment }^{\mathrm{b}}\end{array}$} & \multicolumn{3}{|c|}{$\begin{array}{l}\text { Fast Vegetation } \\
\text { Establishment }\end{array}$} & \multicolumn{3}{|c|}{$\begin{array}{l}\text { Slow Vegetation } \\
\text { Establishment }^{\mathrm{b}}\end{array}$} \\
\hline & $E=10$ & $E=3$ & $E=1$ & $E=10$ & $E=3$ & $E=1$ & $E=10$ & $E=3$ & $E=1$ & $E=10$ & $E=3$ & $E=1$ \\
\hline$B I($ low $Q)$ & 3.24 & 2.42 & 2.14 & 3.26 & 2.54 & 2.11 & - & - & - & - & - & - \\
\hline Mean $B I$ & 3.05 & 2.20 & 1.96 & 3.25 & 2.40 & 1.97 & 3.67 & 2.62 & 1.98 & 3.38 & 2.00 & 1.54 \\
\hline$B I($ high $Q)$ & 2.85 & 1.99 & 1.78 & 3.22 & 2.22 & 1.80 & - & - & - & - & - & - \\
\hline$W(\mathrm{~km})$ & 3.61 & 3.46 & 3.03 & 4.28 & 3.59 & 2.95 & 3.81 & 3.30 & 2.96 & 4.96 & 3.78 & 3.19 \\
\hline$W_{0}(\mathrm{~km})$ & 5.57 & 3.94 & 3.34 & 6.07 & 4.33 & 3.39 & 5.58 & 4.09 & 3.39 & 6.28 & 4.25 & 3.43 \\
\hline$W / W_{0}$ & 0.65 & 0.88 & 0.91 & 0.70 & 0.83 & 0.87 & 0.68 & 0.81 & 0.88 & 0.79 & 0.89 & 0.93 \\
\hline$<h>(\mathrm{m})$ & 5.7 & 6.1 & 6.6 & 5.1 & 5.8 & 6.6 & 6.0 & 6.5 & 7.1 & 5.0 & 5.9 & 6.8 \\
\hline$h_{\max }(\mathrm{m})$ & 21.5 & 25.4 & 23.8 & 22.7 & 23.2 & 25.4 & 22.8 & 25.8 & 26.6 & 23.3 & 26.3 & 28.5 \\
\hline$R(\mathrm{~m})$ & 14.5 & 13.5 & 13.0 & 14.8 & 13.0 & 14.1 & 13.4 & 14.3 & 14.0 & 13.2 & 13.3 & 13.5 \\
\hline$\%$ Veg & 40.7 & 6.4 & 4.4 & 14.8 & 6.9 & 4.3 & 28.1 & 13.9 & 7.7 & 2.2 & 0.5 & 0.0 \\
\hline$\Delta z>2 \mathrm{~m}$ & 63.9 & 93.7 & 95.8 & 69.4 & 88.4 & 91.7 & 59.1 & 74.3 & 90.0 & 87.4 & 94.6 & 98.8 \\
\hline$\Delta z>10 \mathrm{~m}$ & 11.4 & 33.2 & 33.1 & 21.4 & 22.2 & 38.0 & 17.4 & 24.2 & 28.9 & 16.5 & 32.6 & 60.2 \\
\hline
\end{tabular}

${ }^{a}$ Variable discharge simulations use the baseline hydrologic regime.

${ }^{\mathrm{b}}$ Parameterizations of vegetation are slow establishment $\left(T_{\text {veg }}=10\right.$ years, $\left.H_{c r}=0.1 \mathrm{~m}\right)$ and fast establishment $\left(T_{v e g}=6\right.$ years, $\left.H_{c r}=0.3 \mathrm{~m}\right)$. Metrics of channel morphology: braiding index $(B I)$ at low discharge (low $Q$ ), high discharge (high $Q$ ), and averaged across all flow stages (Mean $B I$ ), water surface width at high flow $(W)$, total channel width including emergent bars and islands $\left(W_{0}\right)$, mean depth at high flow $\left(\langle h>)\right.$, maximum depth at high flow $\left(h_{\max }\right)$, mean crosssectional topographic relief $(R)$, percentage of total width covered by vegetation (\%Veg), percentage of channel area experiencing $>2 \mathrm{~m}$ or $>10 \mathrm{~m}$ of bed level change in 50 years $(\Delta z>2 \mathrm{~m}, \Delta z>10 \mathrm{~m})$. With the exception of the latter parameters, all metrics were calculated over the final 100 years of each simulation.

the fraction of the channel that experiences $>2 \mathrm{~m}$ of bed level change over a 50 year period (Table 2).

[38] These results imply that hydrologic regime is likely an important control on bar stability and channel morphology in large anabranching rivers. Moreover, they show that feedbacks between flow variability, bank erodibility, and vegetation development in the model lead to significant differences in bar and island morphodynamics for rivers characterized by the same slope, grain size, and roughness conditions. These feedbacks appear physically realistic
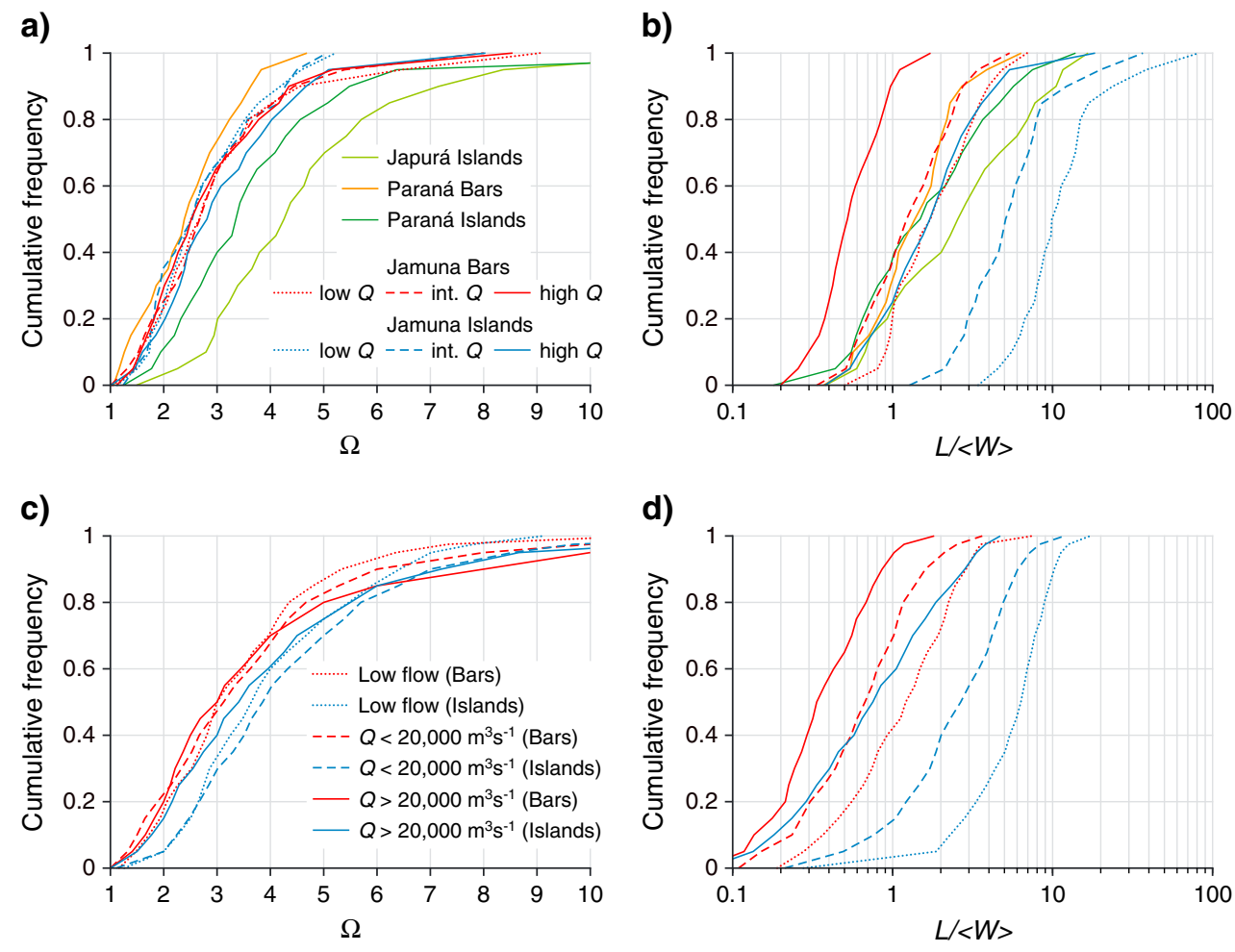

Figure 9. (a and b) Cumulative frequency distributions of bar shape $(\Omega)$ and dimensionless bar length $(L /<W>$ ) for natural anabranching rivers; and (c and d) model simulations conducted using the baseline parameterization, but with $E=10$. Bars and islands are distinguished on the basis of the absence (bars) or presence (islands) of vegetation. Three distributions are shown for the Jamuna representing low (February), intermediate (November), and high (September) flow conditions. 


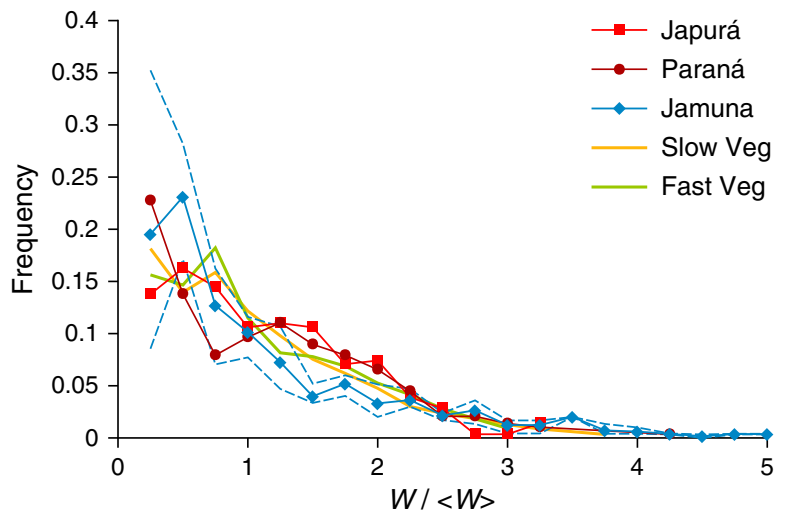

Figure 10. Frequency distributions of dimensionless channel branch width (branch width/mean width of all branches in a river reach) for natural rivers and model simulations conducted using the baseline model parameterization with fast and slow rates of vegetation establishment. The solid line for the Jamuna represents the average width distribution for low, intermediate, and high flow conditions. Dashed lines indicate the maximum and minimum frequencies for the Jamuna for these three water levels.

despite the simple parameterizations of vegetation and bank erosion implemented herein.

\subsection{Evaluation of Modeled Channel Morphology}

[39] Evaluation of models that simulate large river morphodynamics can be difficult for a number of reasons. First, the data required to define initial and boundary conditions and assess model results are rarely available, particularly where predictions of channel change are made for real-world prototypes over periods of decades to centuries. Second, where data do exist, they may not be suitable for model evaluation. For example, although braided stream laboratory experiments may provide data on channel evolution [e.g., Ashmore, 1982; Fukuoka, 1989; Hoey and Sutherland, 1991; Warburton and Davies, 2006] for known initial and boundary conditions, such experiments are generally for gravel-bed river prototypes. Consequently, comparison with experimental data will not enable an assessment of model performance in the context of the large sand-bed rivers, which form the focus of this study. Third, due to the nonlinear nature of fluvial form-process feedbacks, attempts to apply models to simulate spatial patterns of erosion and deposition and match these with observed morphologic changes at specific locations are unlikely to succeed [Kleinhans, 2010]. Instead, it is more appropriate to assess model realism in terms of the statistical characteristics of channel morphology. With these limitations in mind, model realism was assessed using a twofold strategy. In this section, quantitative metrics of channel form (width, depth, and bar/island geometry) for simulated rivers are compared with equivalent data from a number of large anabranching rivers. Following this, in section 3.5, mechanisms and rates of bar and island evolution in model simulations are compared with observations of channel change in large sand-bed rivers derived from satellite imagery.

[40] Figure 9 shows cumulative frequency distributions of bar and island shape $(\Omega)$ and dimensionless length (bar length divided by the mean width of all individual channels in a reach) for selected rivers and for model output. Model results are shown in Figures 9c and 9d for a simulation conducted using the baseline parameterization, but with high bank erodibility $(E=10)$. The channel planform morphology for this model run is shown in Figure 8c. Figure 9a shows that bar shapes are similar for the natural rivers considered here and are also largely independent of stage in the Jamuna. Median values of bar shape $\left(\Omega_{50}\right)$ for natural sandbars vary between 2.39 (Paraná) and 2.67 (Jamuna at both low and high stage). Islands tend to be more elongate than bars, with median shape values of 4.26 (Japurá), 3.35 (Paraná), and 2.51 to 2.81 (Jamuna at low and high stages, respectively). Similar values have been reported by Sambrook Smith et al [2005] for six large sand-bed rivers (mean values of $\Omega=2.0$ to 4.0 ), by Orfeo and Stevaux [2002] for a combined data set of bars and islands in the Paraná $\left(\Omega_{50}=3.7\right)$, and by Kelly [2006] for a large braided river data set (mean values of $\Omega=4.5$ to 5.0 for all rivers and 3.0 to 4.0 for large sand-bed rivers). Modeled bar shape distributions cover a similar range and are also somewhat independent of discharge. For example, for the results shown in Figure $9 \mathrm{c}, \Omega_{50}=3$ at both low and high flows, while $\Omega_{50}=3.12$ at intermediate flows. Simulations conducted with different bank erodibilities and rates of vegetation colonization produce similar bar shape distributions. Moreover, bar shape statistics appear to be independent of model grid cell aspect ratio, as discussed above. As in the case of natural channels, simulated islands tend to be more elongate than bars, and for the results shown in Figure $9 \mathrm{c}, \Omega_{50}$ varies with discharge between 3 (high flow) and 3.86 (intermediate flow). Dimensionless bar and island lengths in nature and in model simulations are characterized by greater variability than bar shapes and show much stronger dependence on water level. Median island lengths are typically $10-20 \%$ greater than for bars in the model and in the Paraná, whereas in the Jamuna vegetated islands are significantly longer than sandbars (median island lengths are typically 3-10 times greater than median bar lengths). However, small and large islands in nature may not have the same genetic origin, and model simulations are not long enough to generate islands by floodplain dissection. Moreover, island length tends to increase over time, as small islands merge and become streamlined by lateral erosion (see section 3.5). Since model runs extend for periods of approximately 500 years or less, very large islands may not have sufficient time to develop. Similarly, simulations are typically characterized by a larger proportion of shorter bars than the natural channels examined here, which may reflect an increase in the frequency of more complex bars in nature that are the product of multiple phases of bar accretion. Despite these differences, in other respects, simulated and natural rivers show good agreement in terms of bar and island geometry.

[41] Figure 10 shows frequency distributions of channel width for the Jamuna, Paraná, and Japurá and for two model simulations. Data for the natural rivers were derived by digitizing all channels across a series of equally spaced cross sections over $\sim 100 \mathrm{~km}$ river reaches. The distribution of individual channel widths was then nondimensionalized by the average of the individual widths. Data shown in Figure 10 for the Jamuna represent the average frequencies for high, intermediate, and low stage (solid line) and the maximum and minimum frequencies associated with these three flow stages (dashed lines). Width distribution data were extracted from the baseline model run and from a second simulation, identical to the 


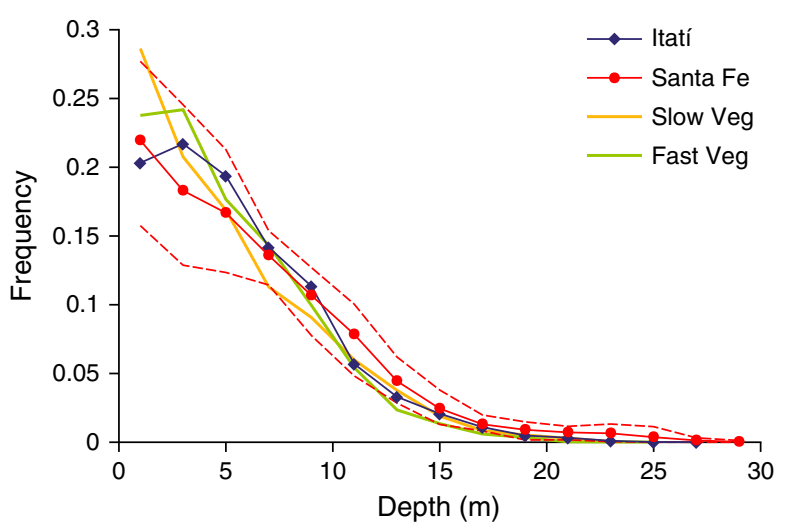

Figure 11. Modeled and observed frequency distributions of channel depth. Distributions are presented for the two reaches of the Rio Paraná near to Itatí and Santa Fe. Dashed lines represent the maximum and minimum frequencies for the reach at Santa Fe, derived using eight bathymetric surveys conducted over the period from 1920 to 2000. These data were provided courtesy of Prof. M. Amsler, Dr. R. Szupiany, and Dirección Nacional de Vias Navegables. Modeled depth distributions are shown for simulations conducted using the baseline model setup, but with $E=1$ and with parameterizations that promote fast vegetation establishment $\left(T_{\text {veg }}=6\right.$ years, $\left.H_{c r}=0.3 \mathrm{~m}\right)$ and slow vegetation establishment $\left(T_{v e g}=10\right.$ years, $\left.H_{c r}=0.1 \mathrm{~m}\right)$.

baseline except with more rapid vegetation colonization $\left(T_{\text {veg }}=6\right.$ years, $\left.H_{c r}=0.3 \mathrm{~m}\right)$. Frequency distributions for both natural and modeled rivers are characterized by an exponential decline in frequency for larger channels. Overall, modeled width distributions are consistent with field data, although there is a tendency for the smallest channels to be underrepresented in the simulated channel morphology, particularly when compared with the data for the Jamuna at high flow, when bar top channels are inundated. This may reflect a physical limit on the minimum channel size that can be represented by the model for any given grid resolution. For example, channels narrower than one to two grid cells (typically 40-80 m) cannot be resolved by the model. Moreover, channel edge cells convey relatively less discharge where the channel is not aligned parallel to the grid lines, as a consequence of which channels that are represented by few cells convey little discharge and so are more likely to infill due to their low capacity for sediment transport. For this reason, channels narrower than three to four grid cells (approximately $200 \mathrm{~m}$ ) are likely to be under-represented in the modeled width distributions.

[42] Figure 11 compares frequency distributions of flow depth for two model simulations with distributions for two reaches of the Rio Paraná. Because of the very low water surface slope of the modeled and natural rivers $\left(5 \mathrm{~cm} \mathrm{~km}^{-1}\right.$ in both cases), these depth distributions are essentially equivalent to bed elevation distributions; hence, this comparison enables a partial assessment of the statistical distribution of modeled bathymetry. Model results are shown for two simulations. These differ from the baseline model run in that they were conducted with low bank erodibility $(E=1)$ in order to yield channel widths similar to those for the reaches of the Paraná considered here (mean widths in the range $2-3 \mathrm{~km}$ ). Simulations examined channel morphology for both slow and fast parameterizations of vegetation colonization. Depth data for a $30 \mathrm{~km}$ reach of the Rio Paraná at Itatí were obtained from a previous application of the hydrodynamic model, which is described elsewhere [Nicholas et al., 2012, Figure 1]. Data for the Paraná near Santa Fe were provided courtesy of M. Amsler, R. Szupiany, and Dirección Nacional de Vias Navegables and were derived from eight bathymetric surveys conducted over the period since 1920 [cf. Ashworth and Lewin, 2012, Figure 16, p. 102]. The eight surveys were used to derive an average depth distribution and upper and lower limits on the frequency in each depth class (dashed lines in Figure 11). Depths in these bathymetric surveys have been corrected using the nearby stage gauge to be equivalent to those associated with a discharge of $15,100 \mathrm{~m}^{3} \mathrm{~s}^{-1}$, which is the discharge modeled at the Itatí reach. Flow depth distributions for the model simulations were also generated for this discharge. Figure 11 illustrates that both reaches of the Rio Paraná and both model runs have very similar depth distributions, characterized by a near-linear decline in frequency for areas shallower than a threshold depth of approximately $12 \mathrm{~m}$. For deeper flows, there is a sharp decline in frequency down to a maximum depth of approximately $25-28 \mathrm{~m} \mathrm{(30} \mathrm{m}$ at Santa Fe, where the channel passes through a flow constriction that promotes bed scour). The close agreement between modeled and natural channel depth distributions is not in itself a demonstration that the modeled channel bathymetry is realistic. However, in combination with the bar geometry and channel width metrics outlined above, the depth distributions shown in Figure 11 provide further confidence that the model is reproducing characteristic geometries and morphologies of large anabranching sand-bed rivers.

\subsection{Comparison of Modeled and Observed Bar and Island Morphodynamics}

[43] This section examines modeled and observed channel dynamics and focuses predominantly on process-form interactions at the bar scale. Figure 12 illustrates mechanisms and rates of modeled bar and island evolution over a period of 200 years for a $16 \mathrm{~km}$ section of river. The first stage of sandbar initiation typically involves migration of a sediment lobe (unit bar), which emerges at the water surface due to bed aggradation and/or a drop in stage. Such incipient bars typically form on the crest of the leading edge of migrating sediment lobes (e.g., upstream of label $\mathrm{U}$ in Figures 12a and 12d). Flow diverges around such features, transporting sediment downstream around either side of the stalled lobe crest and creating two new sediment lobes. These lobes continue to migrate, forming limbs that extend downstream of the bar head for distances of several hundred meters to a few kilometers, giving newly initiated sandbars a characteristic $v$-shape (see bar near label W in Figures $12 \mathrm{~b}$ and 12c). Such v-shaped bars are evident in model simulations over a range of scales, from approximately $300 \mathrm{~m}$ (bars near label $\mathrm{X}$ in Figures $12 \mathrm{~g}$ and $12 \mathrm{i}$ ) up to approximately $2.5-3 \mathrm{~km}$ (bar near label W in Figure 12c). Unit bars and, subsequently, compound bars form in areas of reduced velocity (typically in flow expansions downstream of bars or islands that confine the flow and promote local bed scour) and migrate downstream as they grow. Many such bars are transient features that are eroded when overtopped during flood stage, or which migrate downstream into a channel thalweg where sediment transport capacity is high (e.g., bars that form near $U$ in 
a) $49 y$

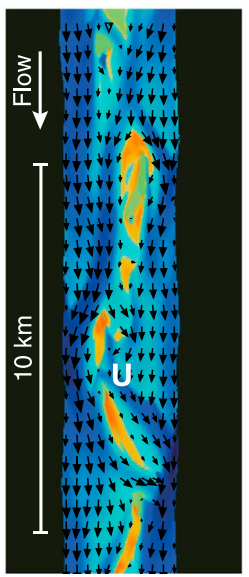

g) $123 y$

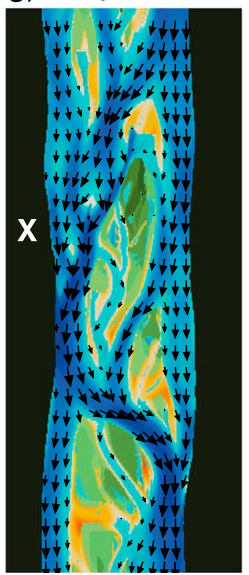

b) $65 \mathrm{y}$

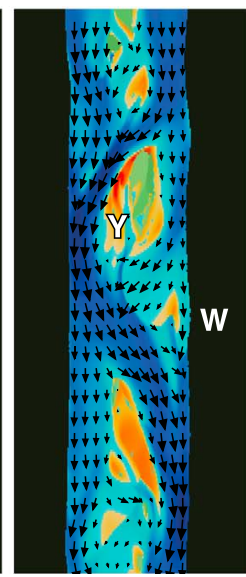

h) $130 y$

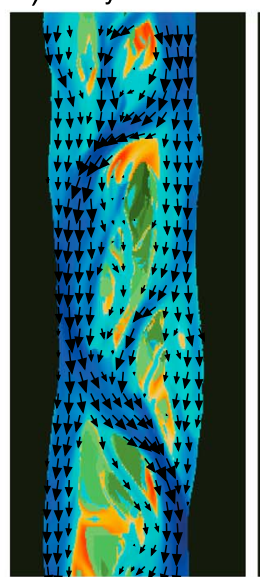

c) $71 \mathrm{y}$

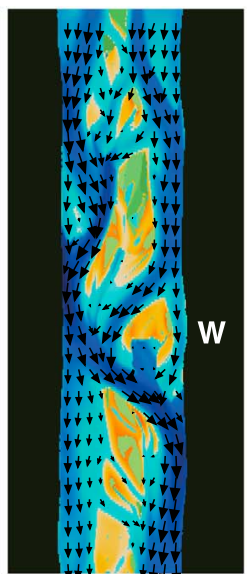

i) $138 \mathrm{y}$ d) $91 \mathrm{y}$

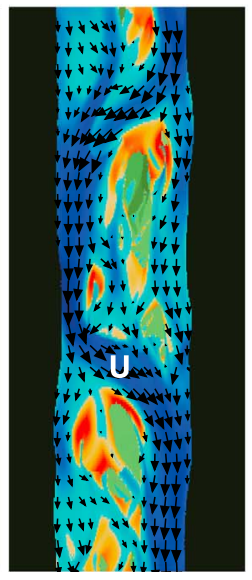

j) $171 \mathrm{y}$

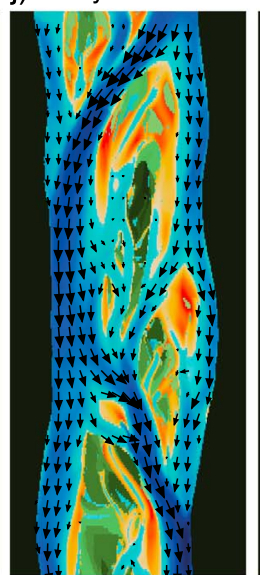

e) 104 y

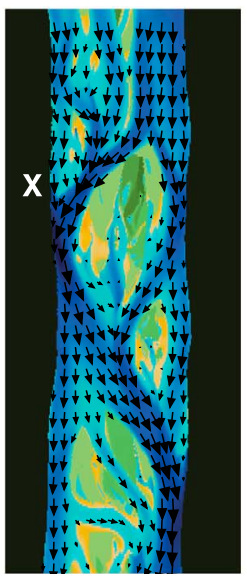

k) $232 \mathrm{y}$

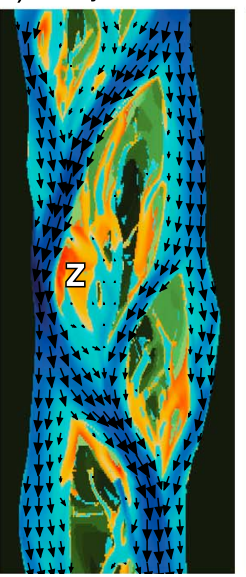

f) $119 y$

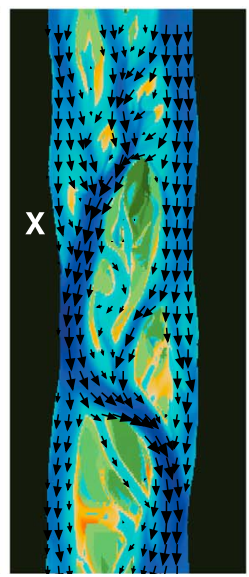

I) $249 \mathrm{y}$
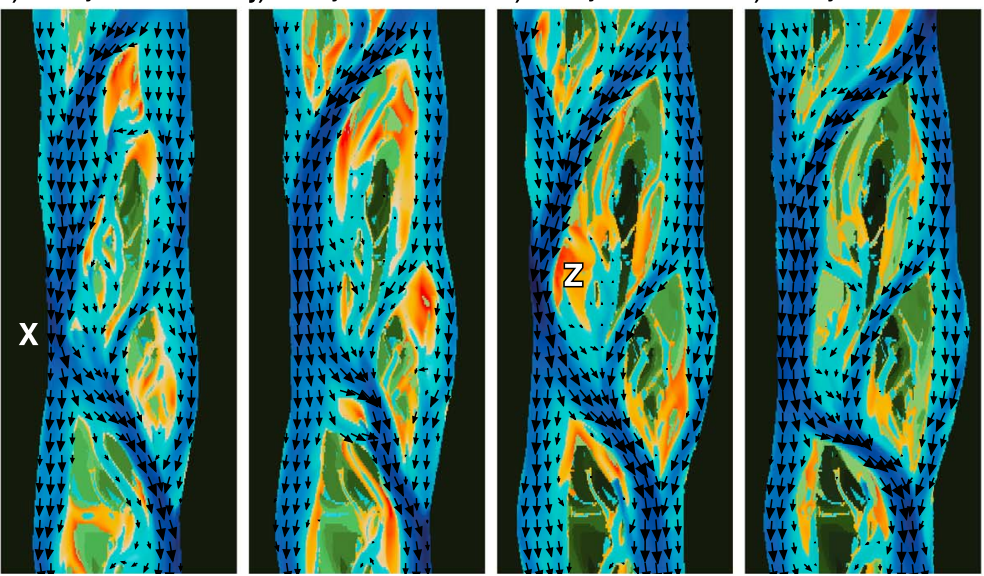

o Vegetated surface age $200 y$

Figure 12. Simulated sequence of channel change for a $16 \mathrm{~km}$ river reach over a period of 200 years using the baseline model parameterization but with rapid vegetation establishment. Labels $\mathrm{U}$ and $\mathrm{W}$ to $\mathrm{Z}$ indicate locations that are referred to in the text. Vectors show the depth-averaged flow velocities at intervals of $300 \mathrm{~m}$ across the channel. Vector length is linearly proportional to velocity magnitude, the maximum value of which in any image is $1.67 \mathrm{~m} \mathrm{~s}^{-1}$. All images show low flow conditions (a discharge of $10,000 \mathrm{~m}^{3} \mathrm{~s}^{-1}$ ). Times given for each panel are relative to the start of the simulation. The scale bar for vegetated surface age is truncated to show a maximum age of 200 years.

Figures 12a and 12d, and near $\mathrm{X}$ in Figures $12 \mathrm{e}-12 \mathrm{i}$ never stabilize). In contrast, bars that form in wide flow expansions, such as in the lee of a large upstream island (e.g., island $\mathrm{Y}$ in Figure 12b), grow vertically and become stabilized by vegetation (e.g., the bar near $\mathrm{W}$ in Figure 12c, which becomes vegetated and then persists over the rest of this simulation). This process occurs over a period of approximately $20-25$ years and the resulting island grows both by lateral and downstream accretion, the latter being restricted by the meandering thalweg downstream of the island, into which it grows. This island also develops by upstream accretion (Figure $12 \mathrm{j}$ onward), which is encouraged by erosion of the adjacent bank. The island at location $\mathrm{Y}$ in Figure $12 \mathrm{~b}$ exhibits a complex sequence of evolution, which involves multiple phases of growth by bar head and lateral accretion (e.g., in Figures $12 \mathrm{~d}$ and $12 \mathrm{~g}-12 \mathrm{j}$ ). At other times, this island is eroded laterally and is streamlined by the flow (e.g., between Figures $12 \mathrm{e}$ and $12 \mathrm{~h}$ ), although it retains a central older core that becomes progressively elongate in form. This island develops an asymmetric shape, with one longer and more stable limb (on the true left) that forms where velocities are lower. The morphology of the opposite island limb, near the main channel thalweg, is more complex and is composed of multiple vegetated fragments. Accretion in this area is frequently dissected during high flows (e.g., upstream of label Z in Figure 12k), leading to the construction of secondary islands (same location in Figure 121). Many islands are characterized by low lying areas and standing water associated with the slackwater zone that forms between v-shaped compound bar limbs, or topographic lows between multiple phases of bar head or lateral unit bar accretion [cf. Best et al., 2006]. Examples of many of the morphological features evident in model simulations can be seen in Figure 2, including unit bars generated on either side of stalled lobe crests (Figures $2 \mathrm{a}$ and $2 \mathrm{c}$ ), v-shaped bars and compound bars (Figures 2b and 2e), bar head accretion (Figure 2d), 

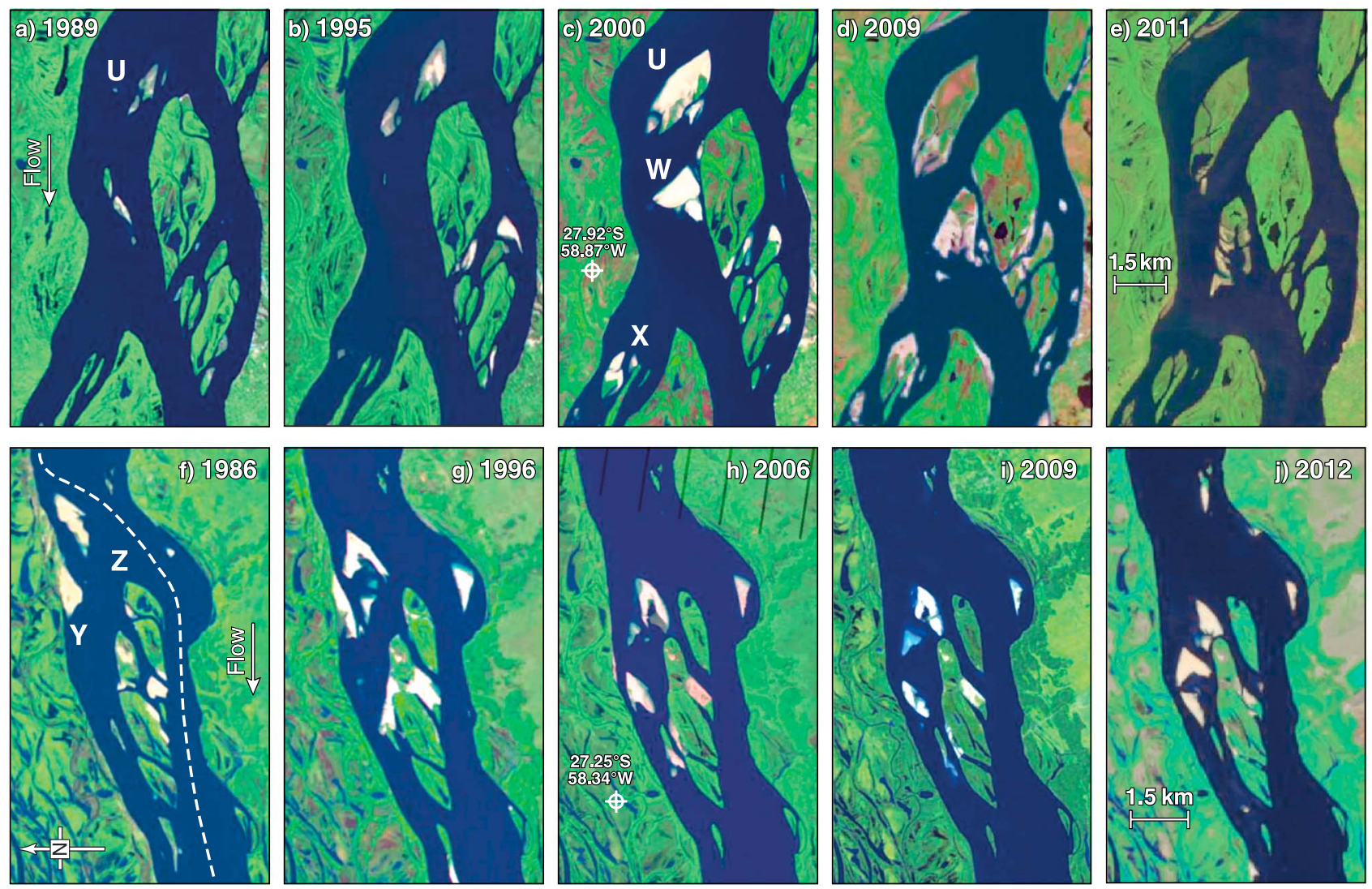

Figure 13. Image sequences showing bar and island evolution for two reaches of the Rio Paraná, Argentina. Labels $\mathrm{U}$ and $\mathrm{W}$ to $\mathrm{Z}$ indicate locations that are referred to in the text. North arrow indicates orientation of all images. The dashed line in panel (f) shows the location of the main channel thalweg. Landsat imagery courtesy of the U.S. Geological Survey.

dissection of bar limbs by overwash channels (Figure 2e), and vegetated islands with central slackwater bodies (Figure 2f).

[44] Mechanisms of channel evolution similar to those described above are evident in the Rio Paraná. For example, Figures 13a-13e provide an example of bar formation in the flow expansion at $U$ (Figure 13a), followed by conversion to a vegetated island over a period of approximately 20 years. This time scale for island formation is comparable to that in model simulations described above. Following its development, flow is confined to the channels on either side of bar $\mathrm{U}$ (Figure 13c), but expands downstream where a further bar forms adjacent to and in the lee of a large vegetated island (at $\mathrm{W}$ in Figure 13c). The head of this new bar is stabilized by vegetation, and it continues to grow in a downstream direction, although the bar tail is periodically dissected to generate new incipient bars (Figure 13e). Farther downstream (near X in Figure 13c), a new bar forms, is stabilized by vegetation, and grows in an upstream direction by bar head accretion over a period of approximately $10-15$ years.

[45] The image sequence in Figures $13 \mathrm{f}-13 \mathrm{j}$ provides further examples of bar initiation in a zone of relatively shallow flow located downstream of the thalweg (indicated by the dashed line in Figure 13f), which crosses from the north bank to the south bank of the river immediately upstream of this region. Several v-shaped compound bars are evident in this area, in addition to a bar that originates as a bank-attached sediment lobe upstream of Y (Figure 13f), and which is subsequently detached by near-bank scour along its edge. Bars in this area migrate downstream, out of the upstream channel thalweg, and accrete onto the upstream and lateral margins of a group of vegetated islands. The latter are also eroded gradually, notably the island adjacent to $Z$ (Figure 13f) that is closest to the main channel thalweg, which is trimmed by approximately $500 \mathrm{~m}$ between 1986 and 2012 . These images also provide estimates of migration rates for several small compound bars that are of the order $110-180 \mathrm{~m}$ $\mathrm{yr}^{-1}$. By comparison, modeled rates of unit bar migration are in the range $50-500 \mathrm{~m} \mathrm{yr}^{-1}$ (mean of approximately $300 \mathrm{~m}$ $\left.\mathrm{yr}^{-1}\right)$, while compound bar migration rates are $0-200 \mathrm{~m} \mathrm{yr}^{-1}$ (mean of approximately $50 \mathrm{~m} \mathrm{yr}^{-1}$ ). The construction of islands by migrating bars (shown in Figures $13 \mathrm{f}-13 \mathrm{j}$ ) in the region immediately downstream of the thalweg as the latter switches to the opposite bank of the river is very similar to the depositional setting of island $\mathrm{Y}$ in Figure $12 \mathrm{~b}$.

[46] The examples outlined above demonstrate that mechanisms of bar and island evolution evident in the model simulations are consistent with observations of these processes in one of the world's largest anabranching rivers. Moreover, the key elements of bar and island morphology appear to be reproduced well by the model. However, as noted in section 1 and elsewhere [Ashworth and Lewin, 2012], large anabranching sand-bed rivers exhibit considerable variety in form, and in rates and styles of evolution. For example, Figure 14 shows changes in channel morphology for a $40 \mathrm{~km}$ reach of the Jamuna River near Bahadurabad, over a period 

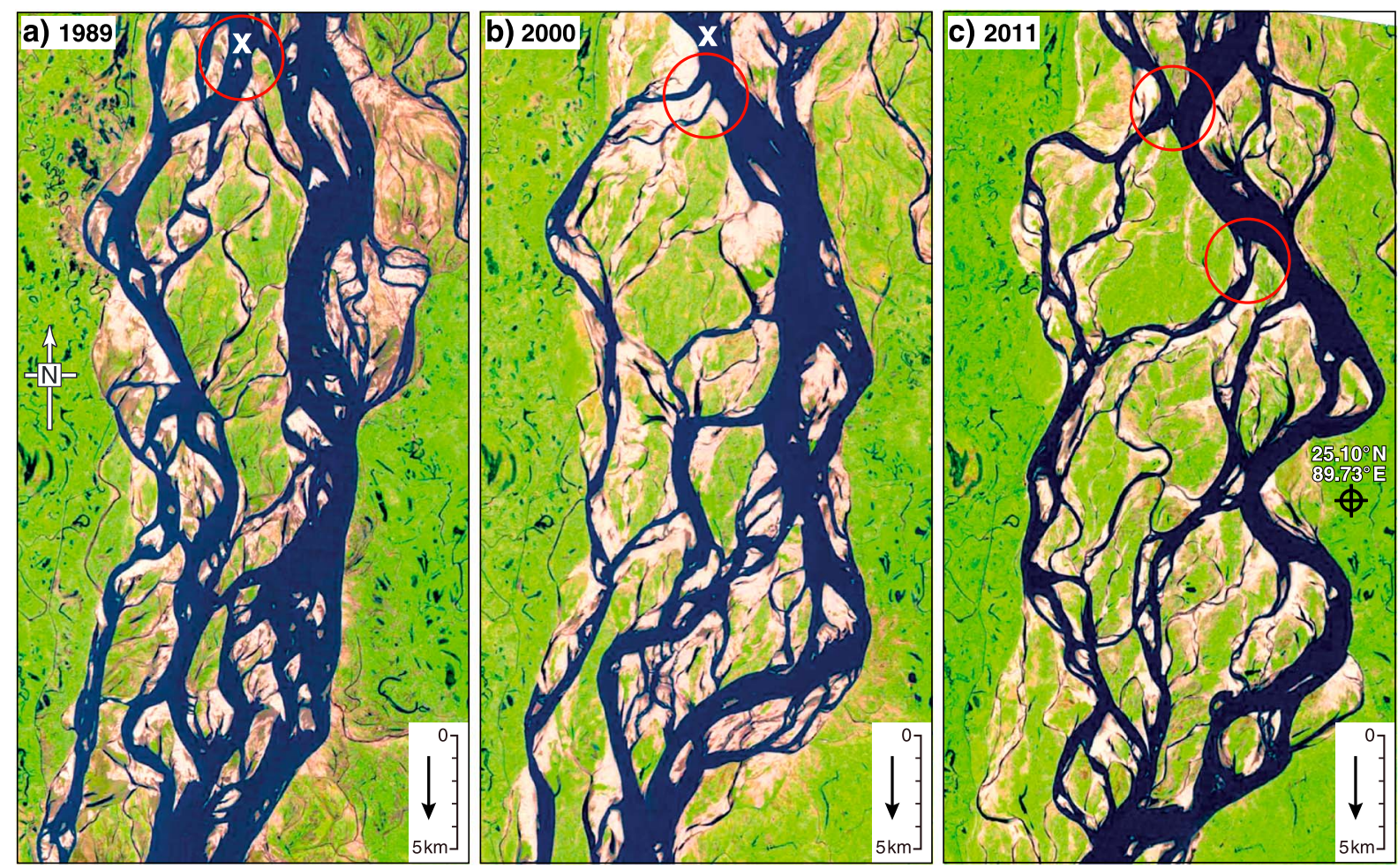

Figure 14. Sequence of images showing channel evolution for a reach of the Jamuna River near Bahadurabad, Bangladesh. Red circles highlight nodal points in the river network. Label X indicates a location that is referred to in the text. Landsat imagery courtesy of the U.S. Geological Survey.

of 22 years. These satellite images illustrate that the morphology of small compound bars in the Jamuna appears very similar to that of bars in the Paraná and other sand-bed rivers [e.g., Ashworth et al., 2000; Sambrook Smith et al., 2006; Horn et al., 2012]. However, the Jamuna differs significantly from the Rio Paraná and many other large rivers in terms of its floodplain-scale morphology and morphological evolution. For example, many studies have documented the rapid rates of bank erosion and bar and island reworking in the Jamuna [Khan and Islam, 2003; Sarker and Thorne, 2006; Ashworth and Lewin, 2012]. Moreover, Figures 14a-14c illustrate a tendency for the distribution of flow between major branches of the river to change over time and for branches to experience significant temporal shifts in sinuosity. These phenomena are linked to changes in the distribution of the flow at nodal points [Thorne et al., 1993] in the channel network (indicated by red circles in Figures 14a-14c), thus as the angle between bifurcates and the upstream flow evolves, the distribution of discharge and sediment adjusts, potentially leading to bifurcate abandonment [Jagers, 2003; Kleinhans, et al., 2012]. In the case of this reach of the Jamuna, the bifurcate that feeds the large channel branch on the west side of the braidplain in 1989 (near label X in Figure 14a) has largely infilled by 2000 (Figure 14b), leading to a substantial reduction in active width of the western channel branch. By 2011 (Figure 14c), water supply to this channel has increased due to reopening of the bifurcate, and creation or reopening of a second feeder channel farther downstream. This process drives significant changes in the width of the major channel branch on the east of the braidplain, which also undergoes substantial changes in sinuosity over this period.
[47] Figure 15 shows modeled channel morphology at four points in time over a period of 175 years for a simulation conducted using the baseline model setup, but with higher bank erodibility $(E=10)$, a steeper channel gradient $\left(S=10 \mathrm{~cm} \mathrm{~km}^{-1}\right)$, and increased bed roughness $\left(C=40 \mathrm{~m}^{0.5} \mathrm{~s}^{-1}\right)$. This combination of $S$ and $C$ was selected to yield a similar distribution of depth-averaged velocity to that obtained in the baseline simulation (note that for steady, uniform flow, velocity is proportion to $C S^{0.5}$ ), but a different distribution of the shear velocity. This simulation is not intended to represent the Jamuna. However, for reasons that are outlined below, it exhibits morphodynamic behavior that is remarkably similar to that of the Jamuna in several respects. For example, while kilometer-scale unit bars and compound bars are present in this simulation, the large-scale evolution of the river is controlled by the abandonment (indicated by a black circle in Figure 15b) and activation (red circles in Figures 15c and 15d) of bifurcates at nodal points in the channel network. This leads to major shifts in the distribution of flow across the braidplain and appears to drive a transition between periods when the river is characterized by a more braided state (e.g., Figures 15a and 15d) and periods when the river has only one major meandering branch at low flow (e.g., Figure 15b). Such transitions between meandering, braided, and anabranching states have been described previously for the Jamuna [Sarker and Thorne, 2006]. In the model simulation, the location of new bifurcation points is generally linked to braidplain topography and the existence of preferential flow paths along formerly abandoned channels. However, the fundamental process mechanism driving this behavior appears to be the degree to which sediment in motion is deflected by gravity in the direction of the transverse bed slope. In the model, this 

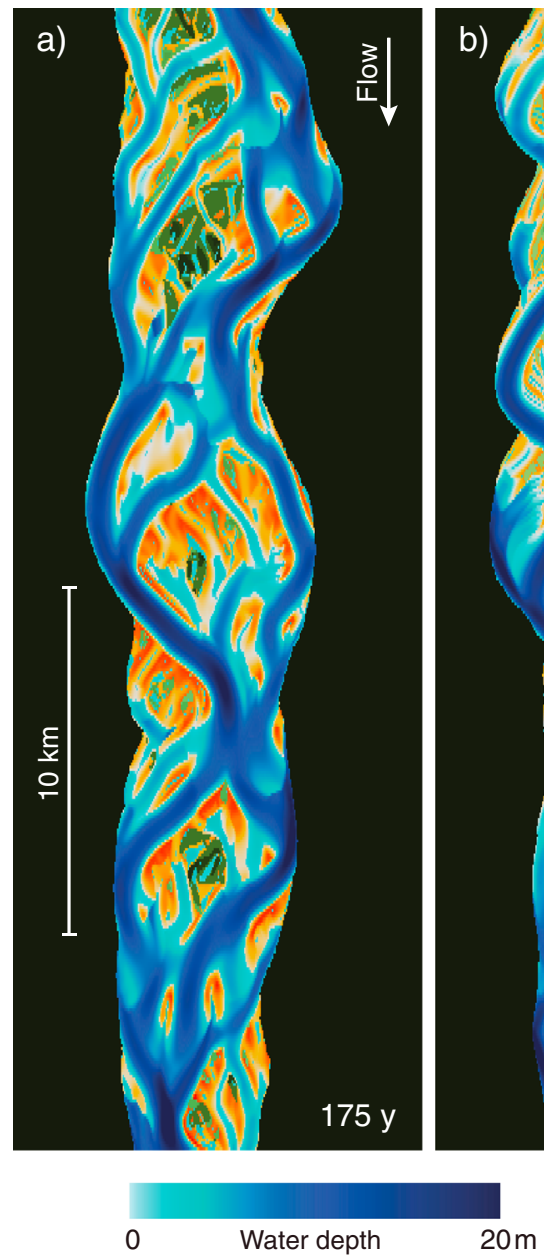

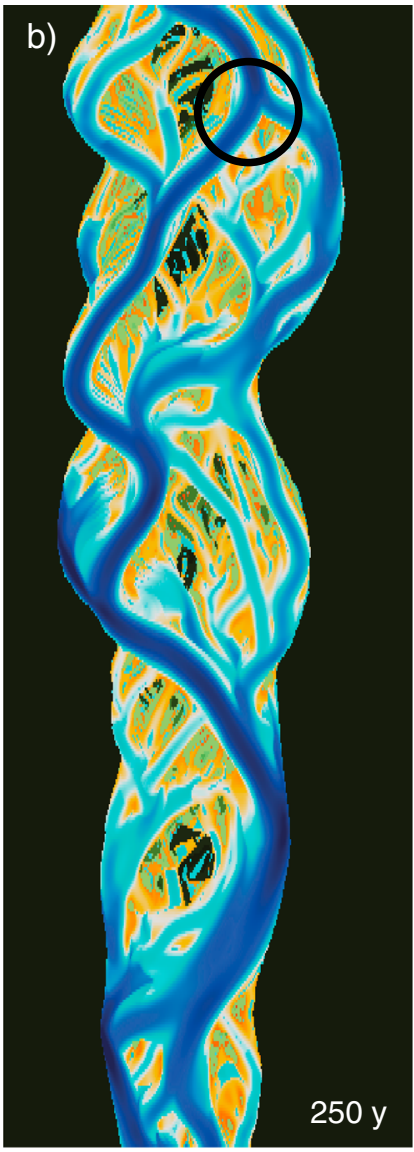

\section{c)}

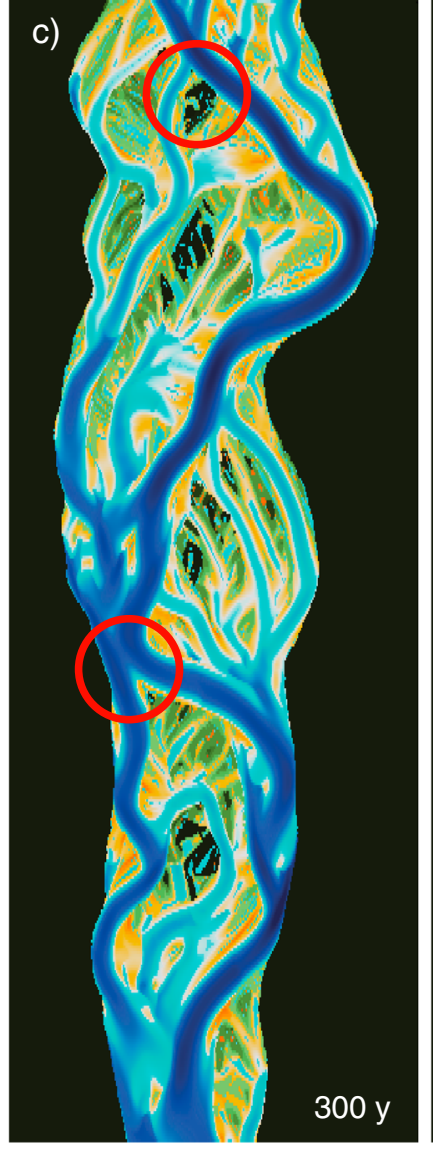

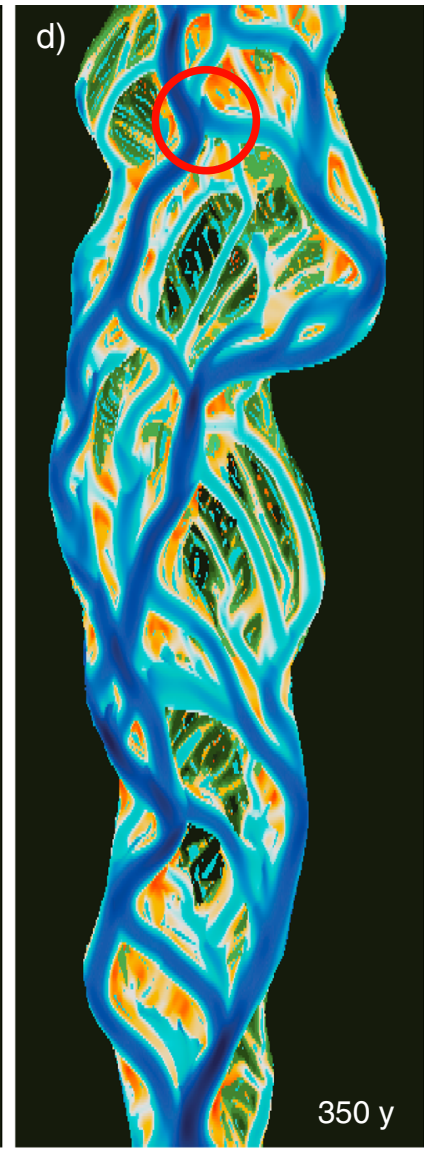

$350 \mathrm{y}$

Figure 15. Simulated channel morphology at four points in time during a model simulation that uses the baseline model parameterization, but with higher bank erodibility $(E=10)$, a steeper channel gradient $\left(S=10 \mathrm{~cm} \mathrm{~km}^{-1}\right)$ and increased bed roughness $\left(C=40 \mathrm{~m}^{0.5} \mathrm{~s}^{-1}\right)$. The black circle indicates a bifurcation in the river network that is being abandoned. Red circles indicate bifurcations that are opening or have recently opened. The scale bar for vegetated surface age is truncated to show a maximum age of 200 years. All images show low flow conditions (a discharge of $10,000 \mathrm{~m}^{3} \mathrm{~s}^{-1}$ ).

gravitational deflection is felt only by sediment moving as bed load; hence, where a large proportion of the sand load is carried in suspension, sediment transport down the lateral slope of bars is suppressed, leading to enhanced vertical aggradation of bar tops. This forces lateral divergence of the flow and the creation of rapidly migrating sinuous channels that rework the braidplain more rapidly than in simulations with lower shear velocities. Compared with the baseline model run, this simulation is also characterized by larger islands and greater bifurcation angles, which favor abandonment of one bifurcate as the bifurcation point migrates. Enhanced suspension of sediment in the simulation shown in Figure 15 is a product of higher shear velocities associated with the $S, C$ combination used. For example, shear velocities are typically $20-50 \%$ higher for this model run than for the baseline simulation, although sediment adaption lengths are short enough for the capacity-based transport formulation to remain valid. In the Jamuna, enhanced sand suspension (relative to the Paraná for example) is likely to be driven by the finer diameter of the sand load $\left(D_{50}=0.25 \mathrm{~mm}\right.$ in the Jamuna compared to $0.3-0.4 \mathrm{~mm}$ for the upper and middle Paraná [Latrubesse, 2008]). Consequently, although the simulation reported in Figure 15 is not intended to mimic the Jamuna, the fundamental mechanism driving the large-scale evolution of the river in this simulation may have direct parallels with mechanisms operating in the Jamuna and linked to the suspension of sand.

\section{Discussion}

[48] To our knowledge, the current study represents a first attempt to apply and evaluate a two-dimensional physicsbased model of bar and island morphodynamics in large sand-bed rivers over centennial time scales. It should be noted that the feasibility of simulating such periods is determined in part by the resolution of the model grid, which controls the hydrodynamic time step via the Courant-FriedrichsLewy stability criterion, and the value of the morphodynamic scaling factor $(M)$. Moreover, the upper limit on $M$ is determined by rates of erosion and deposition within the model domain, which are also controlled by the model grid resolution and the choice of sediment transport relation. Use herein of equation (13) to calculate total sand transport yields rates 


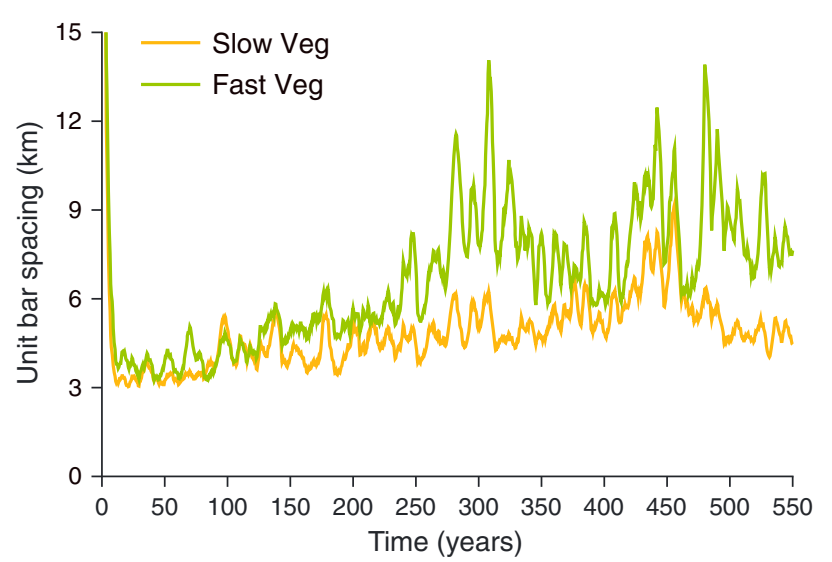

Figure 16. Mean spacing of unit bars in two model simulations that use the baseline model parameterization, but with $E=10$, and with fast and slow rates of vegetation establishment.

of bar and island evolution that appear to match those observed in satellite imagery of the Rio Paraná (Figures 12 and 13). In contrast, although the simulation shown in Figure 15 is not intended to replicate conditions within the Jamuna, comparison between Figures 14 and 15 illustrates that rates of simulated channel change are an order of magnitude lower than observed rates of change. Even accounting for differences in grain size and discharge between the Jamuna and this simulation, this implies that equation (13) may underpredict sediment transport rates in this river substantially [see also Jagers, 2003]. This highlights the need for model calibration in applications involving specific field prototypes and also indicates that neglecting the role of available computational resource, maximum simulation periods are dependent upon river scale (which determines grid size) and dynamism.

[49] The model results presented herein are for idealized (hypothetical) rivers; hence, simulated channel morphodynamics are inevitably less complex than in natural rivers, which experience greater variability in flow and sediment supply, and are influenced by the effects of tectonics, valley floor configuration, and Quaternary environmental change. Modeled bar dynamics are also likely to be less complex than in natural systems due to the simplicity of model process representation. For example, the parameterizations of bank erosion and vegetation effects implemented here neglect many feedbacks and could be refined using existing theory and conceptual models [Darby et al., 2002; Corenblit et al., 2007; Straatsma and Baptist, 2008; Gurnell et al., 2012] to account for spatial and temporal changes in floodplain roughness and sediment trapping, and the relationship between bank erodibility and sediment texture. Similarly, most simulations were based on the assumption of a spatially uniform within-channel Chezy roughness coefficient (in equations (5a) and (5b)), which implies a roughness length scale $\left(k_{s}\right.$ in equation (6)) that is proportional to flow depth. Given that dunes are abundant in sand-bed rivers and have heights that scale approximately with depth [Bridge, 2003], the assumption of a constant value of $C$ is a reasonable first approximation for bed roughness in the absence of an explicit representation of bed forms. However, there is scope for modifying this approach to use a range of more sophisticated equilibrium and nonequilibrium bed form roughness models [e.g., Giri et al., 2007; van Rijn, 2007] in order to represent the complex relationships between depth, transport stage, and dune dimensions that are evident in field data sets [Amsler and Garcia, 1997; Ten Brinke et al., 1999]. In principal, improved representation of river morphodynamics might also be achieved using a three-dimensional modeling approach. However, Schuurman and Kleinhans [2011] compare twoand three-dimensional model simulations of braid bar development and conclude that they produce comparable results. Moreover, Sloff and Mosselman [2012] note that in addition to being computationally expensive, three-dimensional models may not adequately resolve near-bed flow unless implemented at very fine spatial resolutions. This is particularly significant in the case of sand-bed rivers because where approaches based on the three-dimensional Reynolds-averaged Navier-Stokes equations are implemented at resolutions that do not resolve bed topography associated with individual bed forms, roughness representation is problematic [Sandbach et al., 2012] and the stronger physical basis of such models relative to depthaveraged approaches may not result in improved model performance [Nicholas et al., 2012].

[50] The parallels between styles of channel evolution in the Jamuna River and simulation results shown in Figure 15 highlight the potential importance of the suspension of bed material as a control on river morphodynamics and suggest that parameterization of this process deserves greater attention in the future. To achieve this, the model presented herein could be developed to account for multiple sediment size fractions using a nonequilibrium transport formulation [e.g., Begnudelli et al., 2010], which could be important for the representation of fine size fractions transported in suspension and characterized by large adaption lengths. Perhaps more significantly for the representation of bar and island morphodynamics, considerable uncertainty surrounds the parameterization of gravitational deflection of sediment in motion on a sloping bed, and the degree to which such gravitational effects are felt by sediment transported in suspension [Talmon et al., 1995]. Model results indicate that this process could exert a significant influence on braidplain-scale river dynamics, while simulations reported elsewhere for a wider range of grain sizes and channel slopes show that this mechanism may represent a key control on channel pattern in large sand-bed rivers [Nicholas, 2013b]. Despite this, understanding of sand transport on sloping beds is based largely on results from laboratory studies in channels with simple bed configurations [Zimmermann and Kennedy, 1978; Ikeda, 1982; Talmon et al., 1995], and there is a clear need for detailed field measurement programs designed to elucidate this process in more natural settings. Moreover, recent fieldbased research on the Rio Paraná [Szupiany et al., 2012] has highlighted the potential role of inertial effects on suspended bed sediment as a control on bar evolution. Inclusion of this effect within morphodynamic simulations may require the adoption of a multiphase model for flow and suspended sediment transport.

[51] Despite the scope for refining model parameterizations of these processes, there is considerable potential for obtaining generic insight into bar and island morphodynamics, even in the presence of uncertainty in process parameterization. For example, the simulations conducted herein illustrate a range of mechanisms of unit bar generation, which are poorly understood at present due to the difficulty of observing such processes in natural rivers (e.g., bed and bank scour in flow 
confinements or during peak flows, planform flow convergence and divergence promoted by aggrading bars and islands, dissection of compound bar limbs during high flow, detachment of sand previously accreted along bank or bar margins, etc.).

[52] As discussed in section 1, unit bars are recognized as fundamental building blocks of small sand-bed rivers, yet their frequency and role in compound bar construction in large anabranching rivers remain uncertain [Ashworth and Lewin, 2012]. Figure 16 shows temporal changes in the average spacing of unit bars over the duration of two model simulations (these are the model runs shown in Figures $8 \mathrm{a}$ and 8c). Unit bars were mapped using DEMs of difference (DEMoD) generated from successive snapshots of model bathymetry. In such DEMoD, unit bars are clearly identifiable as lobate areas of significant aggradation associated with migrating avalanche faces. By combining analysis of DEMoD with the modeled flow field, individual migrating avalanche faces can be identified, enabling the calculation of the mean spacing between unit bar fronts throughout a simulation. Figure 16 shows that during the early phase of both simulations, there is a rapid decline in bar spacing, which represents the initial development and propagation of unit bars throughout the model domain. Thereafter, mean unit bar spacing is similar in both simulations for approximately 200-250 years. However, in the final 300 years of the model run in which the parameterization of vegetation colonization promotes rapid conversion of compound bars to vegetated islands, there is a substantial increase in unit bar spacing (i.e., a reduction in unit bar frequency). This tendency reflects the fact that mechanisms of unit bar generation, as outlined by Bridge [2003] and observed here, are associated with local channel configurations that are inherently unstable. Consequently, an increase in channel stability, such as that associated with the development and stabilization of large vegetated islands, reduces the frequency of unit bar generation and hence increases their mean spacing. During the period between 350 and 400 years in the simulation with rapid vegetation establishment, several large islands were eroded leading to a short-lived phase of channel instability and associated unit bar generation. In contrast, in the simulation where vegetation establishment is slow, the channel remains in a more dynamic, braided state, and unit bar spacing does not increase substantially. These results suggest that unit bars may be less common in some large sand-bed rivers, such as the Rio Paraná, due to the slow rate of channel evolution and relative stability, which inhibits unit bar generation. However, the relationship between channel stability and unit bar frequency cannot account fully for variations in unit bar frequency. For example, the Rio Negro is a large sandbed river (mean annual discharge approximately $29,000 \mathrm{~m}^{3}$ $\mathrm{s}^{-1}$ ) [Latrubesse and Franzinelli, 2005] characterized by very stable islands and abundant unit bars. Moreover, the dynamic nature of the Jamuna would imply that unit bars should be abundant therein. Indeed, they are certainly evident in satellite images and have been observed in bathymetric surveys [Coleman, 1969]. If unit bars are less abundant in the Jamuna than implied by the dynamic nature of this river [Ashworth and Lewin, 2012], this may reflect a further consequence of sand suspension, which may damp bar morphology where the adaption length of suspended material becomes sufficiently large [Federici and Seminara, 2006]. Clearly, the controls on unit bar frequency in large sand-bed rivers are complex and likely include the stability of channel bed and banks, hydrologic and sediment supply regimes, and intrinsic fluvial processes such as the degree to which bed material can be suspended. Disentangling these effects will require a combination of high spatial resolution, high temporal frequency bathymetric surveys, and detailed monitoring of flow and suspended sediment transport mechanics.

\section{Summary}

[53] Given the lack of previous research into physics-based morphodynamic modeling of large rivers over centennial time scales, the current study represents a first attempt to assess if such modeling is feasible, and whether it can contribute to understanding of bar and island morphodynamics. This work supports the following main conclusions:

[54] 1. The depth-averaged morphodynamic model presented here (HSTAR), which is based on the shallow water equations with a two-fraction sediment transport scheme and relatively simple treatment of bank erosion and vegetation effects, is able to provide a realistic representation of large sand-bed river morphology (e.g., channel width, depth, and bar shape distributions) and dynamics (e.g., mechanisms of unit bar, compound bar and island evolution).

[55] 2. Model results demonstrate that bar and island stability may be sensitive to hydrologic regime, principally because greater variability in flood magnitude encourages the formation of emergent bars that can be converted to stable islands by vegetation colonization.

[56] 3. Simulations illustrate a range of mechanisms of unit bar generation that have been difficult to observe in field settings, all of which are promoted by local bed and/or bank instabilities, and are often associated with planform flow convergence and divergence. This link between unit bar generation and channel instability provides a potential explanation for the reduced frequency of unit bars observed in some large anabranching rivers that are characterized by stable vegetated islands and slow rates of channel change.

[57] 4. The morphology of large sand-bed rivers is sensitive to the channel shear velocity distribution, which controls the suspension of sand and gravitational steering of sediment by the local bed topography. Model results show that these effects influence vertical rates of bar aggradation and determine the role of bifurcation dynamics as a control on the evolution of the channel network. This observation is consistent with the different styles of multithread river evolution evident in natural sand-bed channels, such as the Rio Paraná and Jamuna River.

[58] 5. Model results are sensitive to the parameterization of the processes outlined in (4) above and to the representation of bed roughness. Moreover, considerable uncertainty surrounds these parameterizations and the associated benefits of accounting for the effects on flow and sediment transport of spatial and temporal variations in alluvial bed forms. Development and evaluation of more robust parameterisations requires the collection of high-resolution process data sets and, critically, DEMs of river bathymetry collected over a range of time scales (from days to decades). Such data are required to resolve the interactions between process-form feedbacks operating at bed form, bar, and whole river scales.

[59] Acknowledgments. We thank the UK Natural Environment Research Council (NERC) for support under grant NE/I023228/1 that funded work on the Jamuna River, Bangladesh, and grant NE/E016022/1 


\section{NICHOLAS ET AL.: BAR AND ISLAND MORPHODYNAMICS IN MEGARIVERS}

that funded work on the Rio Paraná, Argentina, together with colleagues Mario Amsler, Jim Best, Rich Hardy, Stuart Lane, Oscar Orfeo, Dan Parsons, Arjan Reesink, and Ricardo Szupiany. Calculations for this study were performed using the University of Exeter Supercomputer. We are grateful to Chris Simpson of Fulcrum Graphics Communications Inc., Vancouver, BC, for sourcing the images in Figure 13. Tom Coulthard, Edgardo Latrubesse and one anonymous reviewer provided valuable comments on the manuscript.

\section{References}

Allmendinger, N. E., J. E. Pizzuto, N. Potter, T. E. Johnson, and W. C. Hession (2005), The influence of riparian vegetation on stream width, eastern Pennsylvania, USA, Geol. Soc. Am. Bull., 117, 229-243.

Amsler, M. L., and M. H. Garcia (1997), Sand-dune geometry of large rivers during floods-Discussion, J. Hydraul. Eng., 123, 582-585.

Amsler, M. L., C. G. Ramonell, and H. A. Toniolo (2005), Morphologic changes in the Paraná River channel (Argentina) in the light of climate variability during the 20th century, Geomorphology, 70, 257-278.

Amsler, M. L., E. C. Drago, and A. R. Paira (2007), Fluvial sediments: Main channel and floodplain interrelationships, in The Middle Paraná River. Limnology of a Subtropical Wetland, edited by M. H. Iriondo, J. C. Paggi, and M. J. Parma, 123-141, Springer-Verlag, Berlin.

Ashmore, P. E. (1982), Laboratory modelling of gravel braided stream morphology, Earth Surf. Processes Landforms, 7, 201-225.

Ashmore, P. E. (1991), How do gravel-bed rivers braid?, Can. J. Earth Sci., $28,326-341$

Ashworth, P. J., and J. Lewin (2012), How do big rivers come to be different?, Earth Sci. Rev., 114, 84-107.

Ashworth, P. J., J. L. Best, J. E. Roden, C. S. Bristow, and G. J. Klaassen (2000), Morphological evolution and dynamics of a large, sand braid-bar Jamuna River, Bangladesh, Sedimentology, 47, 533-555.

Ashworth, P. J., G. H. Sambrook Smith, J. L. Best, J. S. Bridge, S. N. Lane, I. A. Lunt, A. J. H. Reesink, C. J. Simpson, and R. E. Thomas (2011), Evolution and sedimentology of a channel fill in the sandy braided South Saskatchewan River and its comparison to the deposits of an adjacent compound bar, Sedimentology, 58, 1860-1883.

Assine, M. L., and A. Silva (2009), Contrasting fluvial styles of the Paraguay River in the northwestern border of the Pantanal wetland Brazil, Geomorphology, 113, 189-199.

Begnudelli, L., A. Valiani, and B. F. Sanders (2010), A balanced treatment of secondary currents, turbulence and dispersion in a depth-integrated hydrodynamic and bed deformation model for channel bends, Adv. Water Resour., $33,17-33$.

Bernini, A., V. Caleffi, and A. Valiani (2006), Numerical modelling of alternate bars in shallow channels, in Braided Rivers: Process, Deposits, Ecology and Management, Special Publication of International Association of Sedimentologists, edited by G. H. Sambrook Smith, J. L. Best, C. S. Bristow, and G. E. Petts, 36, 153-175, Blackwell Publishing Ltd., Oxford, UK.

Bertoldi, W., L. Zanoni, and M. Tubino (2009), Planform dynamics of braided streams, Earth Surf. Processes Landforms, 34, 547-557.

Best, J. L., P. J. Ashworth, C. S. Bristow, and J. E. Roden (2003), Three-dimensional sedimentary architecture of a large, mid-channel sand braid bar Jamuna River, Bangladesh, J. Sediment. Res., 73, 516-530.

Best, J. L., J. Woodward, P. J. Ashworth, G. H. Sambrook Smith, and C. J. Simpson (2006), Bar top hollows: A new element in the architecture of sandy braided rivers, Sediment. Geol., 190(1-4), 241-255, doi:10.1016/ j.sedgeo.2006.05.022.

Best, J. L., P. J. Ashworth, M. H. Sarker, and J. E. Roden (2007), The Brahmaputra-Jamuna River, Bangladesh, in Large Rivers: Geomorphology and Management, edited by A. Gupta, pp. 395-434, John Wiley and Sons, Chichester, UK

Bridge, J. S. (2003), Rivers and Floodplains: Forms Processes and Sedimentary Record, pp. 491, Blackwell Publishing, London.

Bridge, J. S., and I. A. Lunt (2006), Depositional models of braided rivers, in Braided Rivers: Process, Deposits, Ecology and Management, Special Publication of International Association of Sedimentologists, edited by G. H. Sambrook Smith, J. L. Best, C. S. Bristow, and G. E. Petts, vol. 36, pp. 11-50, Blackwell Publishing, Oxford, UK.

Bristow, C. S. (1987), Brahmaputra River: Channel migration and deposition, in Recent Developments in Fluvial Sedimentology, Special Publication of Economic Palaeontologists and Mineralogists, edited by F. G. Ethridge, R. M. Flores, and M. D. Harvey, Society of Economic Paleontologist and Mineralogists, Special Publication, Tulsa, OK, pp. 63-74.

Carling, P., J. Jansen, and L. Meshkova (2013), Multichannel rivers, their definition and classification, Earth Surf. Processes Landforms, doi:10.1002/esp.3419.

Coleman, J. M. (1969), Brahmaputra River: Channel processes and sedimentation, Sediment. Geol., 3, 129-239, doi:10.1016/0037-0738(69)90010-4.
Corenblit, D., E. Tabacchi, J. Steiger, and A. M. Gurnell (2007), Reciprocal interactions and adjustments between fluvial landforms and vegetation dynamics in river corridors: A review of complementary approaches, Earth Sci. Rev., 84, 56-86.

Coulthard, T. J., D. M. Hicks, and M. J. Van de Wiel (2007), Cellular modelling of river catchments and reaches: Advantages, limitations and prospects, Geomorphology, 90, 192-207.

Crosato, A., and M. S. Saleh (2010), Numerical study on the effects of floodplain vegetation on river planform style, Earth Surf. Processes Landforms, $36,711-720$.

Crosato, A., F. B. Desta, J. Cornelisse, F. Schuurman, and W. S. J. Uijttewaal (2012), Experimental and numerical findings on the long-term evolution of migrating alternate bars in alluvial channels, Water Resour. Res., 48, W06524, doi:10.1029/2011WR011320.

Darby, S. E., A. M. Alabyan, and M. J. Van de Wiel (2002), Numerical simulation of bank erosion and channel migration in meandering rivers, Water Resour. Res., 38, 1163, doi:10.1029/2001WR000602.

Day, G., W. E. Dietrich, J. C. Rowland, and A. Marshall (2008), The depositional web on the floodplain of the Fly River, Papua New Guinea, J. Geophys. Res., 113, F01S02, doi:10.1029/2006JF000622.

De Vriend, H. J. (1981), Steady Flow in Shallow Channel Bends Communications on Hydraulics, Delft University of Technology, Delft, The Netherlands, pp. 81-3.

Defina, A. (2003), Numerical experiments on bar growth, Water Resour. Res., 39, 1092, doi:10.1029/2002WR001455.

Deltares (2010), Delft3D-FLOW user manual, version 3.14, Deltares.

Doeschl-Wilson, A. B., and P. E. Ashmore (2005), Assessing a numerical cellular braided-stream model with a physical model, Earth Surf. Processes Landforms, 30, 519-540.

Duan, J. G. (2004), Simulation of flow and mass dispersion in meandering channels, J. Hydraul. Eng., 130, 964-976.

Dunne, T., J. A. Constantine, and M. B. Singer (2010), The role of sediment transport and sediment supply in the evolution of river channel and floodplain complexity, Trans. Jpn. Geomorphological Union, 31-2, 155-170.

Eaton, B. C., and T. R. Giles (2009), Assessing the effect of vegetationrelated bank strength on channel morphology and stability in gravelbed streams using numerical models, Earth Surf. Processes Landforms, 34, 712-724.

Eaton, B. C., R. G. Millar, and S. Davidson (2010), Channel patterns: Braided, anabranching and single-thread, Geomorphology, 120, 353-364.

Engelund, F., and E. Hansen (1967), A Monograph on Sediment Transport in Alluvial Streams, Teknisk Forlag, Copenhagen, pp. 62.

Enggrob, H. G., and S. Tjerry (1999), Simulation of morphological characteristics of a braided river, in Proc. 1st IAHR Conf. River, Coastal and Estuarine Morphodynamics, edited by G. Seminara, and P. Blondeaux, pp. 585-594, Springer, Berlin, Germany.

Fahnestock, R. K., and W. C. Bradley (1973), Knik and Matanuska Rivers, Alaska: A contrast in braiding, in Fluvial Geomorphology, edited by M. Morisawa, State Univ. of N.Y, Binghamton, N.Y., pp. 220-249.

Federici, B., and G. Seminara (2003), On the convective nature of bar instability, J. Fluid Mech., 487, 125-145, doi:10.1017/S0022112003004737.

Federici, B., and G. Seminara (2006), Effect of suspended load on sandbar instability, Water Resour. Res., 42, W07407, doi:10.1029/ 2005WR004399.

Fielding, C. R., P. J. Ashworth, J. L. Best, E. W. Prokocki, and G. H. Sambrook Smith (2012), Tributary, distributary and other fluvial patterns: What really represents the norm in the continental rock record?, Sediment. Geol., 261-262, 15-32.

Fraccarollo, L., and E. F. Toro (1995), Experimental and numerical assessment of the shallow water model for two-dimensional dam-break type problems, J. Hydraul. Res., 33, 843-64.

Fujita, Y. (1989), Bar and channel formation in braided streams, in River Meandering, Water Resources Monograph 12, edited by S. Ikeda and G. Parker, AGU, Washington, DC, pp. 417-462.

Fukuoka, S. (1989), Finite amplitude development of alternate bars, in River Meandering, Water Resources Monograph 12, edited by S. Ikeda and G. Parker, AGU, Washington, DC, pp. 237-265.

Giri, S., S. Yamaguchi, Y. Shimizu, and J. Nelson (2007), Simulating temporal response of bedform characteristics to varying flows, in Proceedings of the 5th IAHR Symposium on River, Coastal and Estuarine Morphodynamics, edited by C. M. Dohmen-Janssen and S. J. M. H. Hulscher, Taylor \& Francis, London, pp. 939-947.

Gupta, A. (Ed) (2007), Large Rivers: Geomorphology and Management, John Wiley and Sons, Chichester, pp. 689.

Gurnell, A. M., G. E. Petts, D. M. Hannah, B. P. Smith, P. J. Edwards, J. Kollmann, J. V. Ward, and K. Tockner (2001), Riparian vegetation and island formation along the gravel-bed Fiume Tagliamento, Italy, Earth Surf. Processes Landforms, 26, 31-62.

Gurnell, A. M., W. Bertoldi, and D. Corenblit (2012), Changing river channels: The roles of hydrological processes, plants and pioneer fluvial 


\section{NICHOLAS ET AL.: BAR AND ISLAND MORPHODYNAMICS IN MEGARIVERS}

landforms in humid temperate, mixed load and gravel bed rivers, Earth Sci. Rev., 111, 129-141.

Harten, A., P. D. Lax, and B. van Leer (1983), On upstream differencing and Godunov-type schemes for hyperbolic conservation laws, SIAM Reviews, $25,35-61$.

Hoey, T. B., and A. J. Sutherland (1991), Channel morphology and bedload pulses in braided rivers: A laboratory study, Earth Surf. Processes Landforms, 16, 447-462.

Horn, J. D., R. M. Joeckel, and C. R. Fielding (2012), Progressive abandonment and planform changes of the central Platte River in Nebraska, central USA, over historical timeframes, Geomorphology, 139-140, 372-383.

Hovius, N., and M. Leeder (1998), Clastic supply to basins, Basin Res., 10, 1-5. Ikeda, S. (1982), Lateral bed load transport on side slopes, J. Hydraul. Div., ASCE, 108, 1369-1373.

Jagers, H. R. A. (2003), Modelling Planform Changes of Braided Rivers, Twente University, pp. 318.

Jang, C.-L., and Y. Shimizu (2005), Numerical simulation of relatively wide, shallow channels with erodible banks, J. Hydraul. Eng., 131, 565-575.

Kalkwijk, J. P. T., and R. Booij (1986), Adaption of secondary flow in nearly horizontal flow, J. Hydraul. Res., 24, 19-37.

Kelly, S. (2006), Scaling and hierarchy in braided rivers and their deposits: Examples and implications for reservoir modelling, in Braided Rivers: Process, Deposits, Ecology and Management, Special Publication of International Association of Sedimentologists, 36, edited by G. $\mathrm{H}$ Sambrook Smith, J. L. Best, C. S. Bristow, and G. E. Petts, 75-106, Blackwell Publishing, Oxford, UK.

Khan, N. I., and A. Islam (2003), Quantification of erosion patterns in the Brahmaputra-Jamuna River using geographical information system and remote sensing techniques, Hydrol. Processes, 17, 959-966.

Kleinhans, M. G. (2010), Sorting out river channel patterns, Prog. Phys. Geogr., 34, 287-326.

Kleinhans, M. G., H. R. A. Jagers, E. Mosselman, and C. J. Sloff (2008), Bifurcation dynamics and avulsion duration in meandering rivers by one-dimensional and three-dimensional models, Water Resour. Res., 44 , W08454, doi:10.1029/2007WR005912.

Kleinhans, M. G., R. I. Ferguson, S. N. Lane, and R. J. Hardy (2012), Splitting rivers at their seams: Bifurcations and avulsion, Earth Surf. Processes Landforms, 38, 47-61, doi:10.1002/esp.3268.

Lanzoni, S. (2000), Experiments on bar formation in a straight flume channel, Water Resour. Res., 36, 3337-3349.

Latrubesse, E. M. (2008), Patterns of anabranching channels: The ultimate end member adjustment of mega rivers, Geomorphology, 101, 130-145.

Latrubesse, E. M., and E. Franzinelli (2002), The Holocene alluvial plain of the middle Amazon River, Brazil, Geomorphology, 44, 241-257.

Latrubesse, E. M., and E. Franzinelli (2005), The late Quaternary evolution of the Negro River Amazon, Brazil: Implications for island and floodplain formation in large anabranching tropical systems, Geomorphology, 70, 372-397.

Lesser, G. R., J. A. Roelvink, J. A. T. M. van Kester, and G. S. Stelling (2004), Development and validation of a three-dimensional morphological model, Coastal Eng., 51, 883-915.

Lewin, J., and P. J. Ashworth (2013), Defining large river channel patterns: Alluvial exchange and plurality, Geomorphology, doi:10.1016/ j.geomorph.2013.02.024.

Liang, Q., G. Du, J. W. Hall, and A. G. L. Borthwick (2008), Flood inundation modelling with an adaptive quadtree grid shallow water equation solver, J. Hydraul. Eng., 134, 1603-1610.

Marciano, R., Z. B. Wang, A. Hibma, and H. J. de Vriend (2005), Modeling of channel patterns in short tidal basins, J. Geophys. Res., 110, F01001, doi:10.1029/2003JF000092.

McArdell, B. W., and R. Faeh (2001), A computational investigation of river braiding, in Gravel-Bed Rivers V, edited by M. P. Mosley, New Zealand Hydrological Society, Wellington, pp. 73-94.

Mertes, L., T. Dunne, and L. Martinelli (1996), Channel floodplain geomorphology along the Solimões-Amazon River, Brazil, Geol. Soc. Am. Bull., 108, 1089-1107.

Milliman, J. D., and R. H. Meade (1983), World-wide delivery of river sediment to the ocean, J. Geol., 91, 1-21.

Mingham, C. G., and D. M. Causon (1998), High resolution finite-volume method for shallow water flows, J. Hydraul. Eng., 124, 605-614.

Murray, A. B., and C. Paola (1994), A cellular model of braided rivers, Nature, 371, 54-57.

Nanson, G. C., and A. D. Knighton (1996), Anabranching rivers: Their cause, character and classification, Earth Surf. Processes Landforms, 21, 217-239.

Nicholas, A. P. (2013a), Modelling the continuum of river channel patterns, Earth Surf. Processes Landforms, doi:10.1002/esp.3431.

Nicholas, A. P. (2013b), Morphodynamic diversity of the world's largest rivers, Geology, 41, 475-478, doi:10.1130/G34016.1.

Nicholas, A. P., and T. A. Quine (2007), Crossing the divide: Representation of channels and processes in reduced-complexity river models at reach and landscape scales, Geomorphology, 90, 318-339.
Nicholas, A. P., et al. (2012), Modelling hydrodynamics in the Rio Paraná, Argentina: An evaluation and inter-comparison of reduced-complexity and physics based models applied to a large sand-bed river, Geomorphology, 169-170, 192-211.

Olesen, K. W., and S. Tjerry (2002), Morphological modelling of the Chaktomuk Junction, in River Flow 2002, edited by D. Bousmar and Y. Zech, IAHR Publication, Balkema, pp. 879-888.

Orfeo, O., and J. Stevaux (2002), Hydrological and morphological characteristics of the middle and upper reaches of the Paraná River (Argentina and Brazil), Geomorphology, 44, 309-322.

Paola, C., K. Straub, D. Mohrig, and L. Reinhardt (2009), The "unreasonable effectiveness" of stratigraphic and geomorphic experiments, Earth Sci. Rev., 97, 1-43.

Parker, G., Y. Shimizu, G. V. Wilkerson, E. C. Eke, J. D. Abad, J. D. Lauer, C. Paola, W. E. Dietrich, and V. R. Voller (2011), A new framework for modeling the migration of meandering rivers, Earth Surf. Processes Landforms, 36, 70-86.

Parsons, D. R., J. L. Best, S. N. Lane, O. Orfeo, R. J. Hardy, and R. Kostaschuk (2007), Form roughness and the absence of secondary flow in a large confluence-diffluence Paraná River, Argentina, Earth Surf. Processes Landforms, 32, 155-162.

Peakall, J., P. J. Ashworth, and J. L. Best (1996), Physical modelling in fluvial geomorphology: Principles, applications and unresolved issues, in The Scientific Nature of Geomorphology, edited by B. L. Rhoads and C. E. Thorn, pp. 221-253, John Wiley and Sons, Chichester.

Potter, P. E. (1978), Significance and origin of big rivers, J. Geol., 86, 13-33.

Ramonell, C. G., M. L. Amsler, and H. Toniolo (2002), Shifting modes of the Paraná River thalweg in its middle/lower reach, Zeitschrift fur geomorphologie Suppl.-Bd., 129, 129-142.

Rozo, M. G., A. C. R. Nogueira, and W. Truckenbrodt (2012), The anastomosing pattern and the extensively distributed scroll bars in the middle Amazon River, Earth Surf. Processes Landforms, 37, 1471-1488.

Sambrook Smith, G. H., P. J. Ashworth, J. L. Best, J. Woodward, and C. J. Simpson (2005), The morphology and facies of sandy braided rivers: Some considerations of scale invariance, in Fluvial Sedimentology VII, Special Publication of International Association of Sedimentologists, edited by M. D. Blum, S. B. Marriott, and S. F. Leclair, Blackwell Publishing Ltd., Oxford, UK, vol. 35, pp. 145-158.

Sambrook Smith, G. H., P. J. Ashworth, J. L. Best, J. Woodward, and C. J. Simpson (2006), The sedimentology and alluvial architecture of the sandy braided South Saskatchewan River Canada, Sedimentology, 53, 413-434.

Sambrook Smith, G. H., P. J. Ashworth, J. L. Best, I. A. Lunt, O. Orfeo, and D. R. Parsons (2009), The sedimentology and alluvial architecture of a large braid bar Río Paraná, Argentina, J. Sediment. Res., 79, 629-642.

Sandbach, S. D., et al. (2012), Application of a roughness-length representation to parameterize energy-loss in 3D numerical simulations of large rivers, Water Resour. Res., 48, W12501, doi:10.1029/2011WR011284.

Sanders, B. F., and S. F. Bradford (2006), Impact of limiters on accuracy of high resolution flow, J. Hydraul. Eng., 132, 87-98.

Sarker, M. H., and C. R. Thorne (2006), Morphological response of the Brahmaputra-Padma-Lower Meghna river system to the Assam earthquake of 1950, in Braided Rivers: Process, Deposits, Ecology and Management, Special Publication of International Association of Sedimentologists, edited by G. H. Sambrook Smith, J. L. Best, C. S. Bristow, and G. E. Petts, Blackwell Publishing, Oxford, UK, vol. 36, pp. 289-310.

Schuurman F., and M. G. Kleinhans (2011), Self-formed braided bar pattern in a numerical model. In: Proceedings of the 7th IAHR conference on River, Estuarine and Coastal Morphodynamics. Beijing, China.

Seminara, G. (1998), Stability and morphodynamics, Meccanica, 33, 59-99. Seminara, G. (2006), Meanders, J. Fluid Mech., 554, 271-297.

Sloff, K., and E. Mosselman (2012), Bifurcation modelling in a meandering gravel-sand bed river, Earth Surf. Processes Landforms, 37, 1556-1566.

Smith, N. D. (1974), Sedimentology and bar formation in the Upper Kicking Horse River, a braided outwash stream, J. Geol., 82, 205-223.

Straatsma, M. W., and M. J. Baptist (2008), Floodplain roughness parameterization using airborne laser scanning and spectral remote sensing, Remote Sens. Environ., 112, 1062-1080.

Stuiksma, N., K. W. Olsen, C. Flokstra, and H. J. De Vriend (1985), Bed deformation in curved alluvial channels, J. Hydraul. Res., 23, 57-79.

Syvitski, J. P. M., and A. Kettner (2011), Sediment flux and the Anthropocene, Phil. Trans. R. Soc. A, 369, 957-975.

Szupiany, R. N., M. L. Amsler, J. Hernandez, D. R. Parsons, J. L. Best, E. Fornari, and A. Trento (2012), Flow fields, bed shear stresses and suspended bed sediment dynamics in bifurcations of a large river, Water Resour. Res., 48, W11515, doi:10.1029/2011WR011677.

Tal, M., and C. Paola (2010), Effects of vegetation on channel morphodynamics: Results and insights from laboratory experiments, Earth Surf. Processes Landforms, 35, 1014-1028. 


\section{NICHOLAS ET AL.: BAR AND ISLAND MORPHODYNAMICS IN MEGARIVERS}

Talmon, A., N. Struiksma, and M. van Mierlo (1995), Laboratory measurements of the direction of sediment transport on transverse alluvial bed slopes, J. Hydraul. Res., 33, 495-517.

Ten Brinke, W. B. M., A. W. E. Wilbers, and C. Wesseling (1999), Dune growth, decay and migration rates during a large-magnitude flood at a sand and mixed sand-gravel bed in the Dutch Rhine river system, in Fluvial Sedimentology VI, Special Publication of International Association of Sedimentologists, edited by N. D. Smith and J. Rogers, pp. 15-32, Blackwell Publishing Ltd., Oxford, UK.

Thomas, R., A. P. Nicholas, and T. A. Quine (2007), Cellular modelling as a tool for interpreting historic braided river evolution, Geomorphology, 90, 302-317.

Thorne, C. R., A. P. G. Russell, and M. K. Alam (1993), Planform pattern and channel evolution of the Brahmaputra River, Bangladesh, in Braided Rivers, edited by J. L. Best and C. S. Bristow, Geol. Soc. London Spec. Publ., 75, 257-276.

Trigg, M. A., P. D. Bates, M. D. Wilson, G. Schumann, and C. Baugh (2012), Floodplain channel morphology and networks of the middle Amazon River, Water Resour. Res., 48, W10504, doi:10.1029/201WR011888.

van der Wegen, M., Z. B. Wang, H. H. G. Savenije, and J. A. Roelvink (2008), Long-term morphodynamic evolution and energy dissipation in a coastal plain, tidal embayment, J. Geophys. Res., 113, F03001, doi:10.1029/2007JF000898.

van Dijk, W. M., W. I. van de Lageweg, and M. G. Kleinhans (2012), Experimental meandering river with chute cutoffs, J. Geophys. Res. 117, F03023, doi:10.1029/2011JF002314. van Leer, B. (1979), Towards the ultimate conservation difference scheme. V. A second-order sequel to Godunov's method, J. Comput. Phys., 32, 101-136.

van Rijn, L. C. (1984), Sediment transport, part II: Suspended load transport, J. Hydraul. Eng., 110, 1613-1641.

van Rijn, L. C. (2007), Unified view of sediment transport by currents and waves I: Initiation of motion, bed roughness, and bed-load transport, J. Hydraul. Eng., 133, 649-667.

Wang, G., J. Xia, and B. Wu (2008), Numerical simulation of longitudinal and lateral channel deformations in the braided reach of the lower Yellow River, J. Hydraul. Eng., 134, 1964-1978.

Wang, H., G. Zhou, and X. Shao (2010), Numerical simulation of channel pattern changes Part II: Application in a conceptual channel, Int. J. Sediment Res., 25, 380-490.

Warburton, J., and T. Davies (2006), Variability of bedload transport and channel morphology in a braided river hydraulic model, Earth Surf. Processes Landforms, 19, 403-421.

Wu, W., and S. S. Y. Wang (2004), Depth-averaged 2-D calculation of flow and sediment transport in curved channels, Int. J. Sediment Res., 19, 241-257.

Xia, J. Q., Z. B. Wang, B. Van Maren, J. J. Zhou, and B. S. Wu (2010), Intercomparison of three morphodynamic models for the lower Yellow River, in River Flow 2010, edited by A. Dittrich et. al., pp. 1085-1093, Bundesanstalt fur Wasserbau, Karlsruhe.

Zimmermann, C., and J. F. Kennedy (1978), Transverse bed slopes in curved alluvial streams, J. Hydraul. Div., ASCE, 104, 33-48. 